\title{
The role of ubiquitination and deubiquitination in cancer metabolism
}

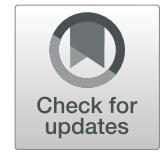

\author{
Tianshui Sun ${ }^{1}$, Zhuonan Liu ${ }^{2}$ and Qing Yang ${ }^{1 *}$ (D)
}

\begin{abstract}
Metabolic reprogramming, including enhanced biosynthesis of macromolecules, altered energy metabolism, and maintenance of redox homeostasis, is considered a hallmark of cancer, sustaining cancer cell growth. Multiple signaling pathways, transcription factors and metabolic enzymes participate in the modulation of cancer metabolism and thus, metabolic reprogramming is a highly complex process. Recent studies have observed that ubiquitination and deubiquitination are involved in the regulation of metabolic reprogramming in cancer cells. As one of the most important type of post-translational modifications, ubiquitination is a multistep enzymatic process, involved in diverse cellular biological activities. Dysregulation of ubiquitination and deubiquitination contributes to various disease, including cancer. Here, we discuss the role of ubiquitination and deubiquitination in the regulation of cancer metabolism, which is aimed at highlighting the importance of this post-translational modification in metabolic reprogramming and supporting the development of new therapeutic approaches for cancer treatment.
\end{abstract}

Keywords: Ubiquitination, Deubiquitination, Cancer, Metabolic reprogramming

\section{Background}

Metabolic pathways are of vital importance in proliferating cells to meet their demands of various macromolecules and energy [1]. Compared with normal cells, cancer cells own malignant properties, such as increased proliferation rate, and reside in environments short of oxygen and nutrient. Correspondingly, metabolic activities are altered in cancer cells to support their malignant biological behaviors and to adapt to stressful conditions, such as nutrient limitation and hypoxia [1]. Cancer metabolism is an old field of research. Warburg effect observed in the 1920s provides a classical example of metabolic reprogramming in cancer [2]. In the past few decades, enhanced biosynthesis of macromolecules, altered energy metabolism, and maintenance of redox homeostasis have been observed to be essential features of cancer metabolism. Altered metabolism in cancer

\footnotetext{
*Correspondence: yangqing_sj@126.com

'Department of Obstetrics and Gynecology, Shengjing Hospital of China Medical University, No. 36, Sanhao Street, Heping District, Shenyang 110004, China

Full list of author information is available at the end of the article
}

cells have aroused increasing attention and interest [3]. Because of the generality of metabolic alterations in cancer cells, metabolic reprogramming is thought as hallmark of cancer, providing basis for tumor diagnosis and treatment [1]. For instance, the application of 18Fdeoxyglucose positron emission tomography is based on tumor cells' characteristic of increased glucose consumption [4]. Inhibition of some metabolic enzymes, such as L-lactate dehydrogenase A chain (LDH-A), have been observed to regress established tumors $[5,6]$. Therefore, research of metabolic reprogramming is of critical importance, which might provide new opportunities for cancer diagnosis and treatment.

Amongst multiple post-translational modification, protein ubiquitination is a common and important process in cells $[7,8]$. Ubiquitination and deubiquitination have been observed to be dysregulated in various types of cancers. Genetic and epigenetic aberrations, such as mutation, amplification and deletion, can be the common causes of dysregulated ubiquitination and deubiquitination in cancer cells [9]. Ubiquitination and deubiquitination can also 
be abnormally regulated by transcriptional, translational or posttranslational mechanisms in cancer cells, exerting oncogenic or anti-cancer roles in carcinogenesis $[7,8,10]$. In recent years, the involvement of ubiquitination and deubiquitination in the regulation of metabolic reprogramming in cancer cells has received a growing body of attention [11]. Given the complexity and importance of both cancer metabolism and protein ubiquitination, the exact roles of protein ubiquitination and deubiquitination in metabolic reprogramming are worth further studies and analyses. The present review will highlight the ubiquitination and deubiquitination system as a regulator of cancer metabolism and discuss future directions focusing on the strategies to improve cancer therapy.

\section{Cancer metabolism}

To satisfy nutrient and energy requirements for cells' survival and growth, metabolic pathways are altered in cancer cells, which is called metabolic reprogramming [1]. Metabolic reprogramming is a highly regulated process [12]. Aberrant activation of mechanistic target of rapamycin complex 1 (mTORC1) is one of the most common alterations in proliferating cancer cells, playing a key role in metabolic reprogramming [12]. Under the stimulation of amino acids, mTORC1 can be activated, which subsequently exerts various biological effects by activation of different downstream targets, such as hypoxia-inducible factor 1 (HIF-1) and sterol regulatory element-binding protein (SREBP) [12, 13]. Proliferating cancer cells require elevated synthesis of protein, lipid and nucleotide. Glycolysis can be upregulated by mTORC1 activation, providing more glycolytic intermediates for biosynthesis of these macromolecules [14]. Moreover, mTORC1 activation promotes glutamine uptake to maintain mitochondrial ATP production [15]. Fatty acids can also supply carbon to the tricarboxylic acid (TCA) cycle to sustain mitochondrial function [16]. PI3K-AKT signaling is the most well-known mechanism for activating mTORC1 [17]. Besides, mTORC1 can be activated or inhibited by various signaling pathways directly or indirectly. For instance, 5'-AMP-activated protein kinase (AMPK) activated by energy shortage is a crucial inhibitor of mTORC1 [18]. What's more, transcription factor c-Myc and p53 also take part in metabolic reprogramming through transcriptional regulation of metabolism-related genes $[19,20]$. Based on multiple regulatory mechanisms, expression or activity of the enzymes involved in glucose, amino acids and fatty acids metabolism are altered, directly contributing to metabolic reprogramming [21]. What's more, the upregulation of various metabolic processes in cancer cells triggers accumulation of reactive oxygen species (ROS) [22]. Transcription factors nuclear factor erythroid 2related factor 2 (NRF2) and HIF-1 play key roles in maintenance of redox homeostasis, keeping ROS in an appropriate level to promote tumor growth rather than inducing damage [23, 24].

Under nutrient rich conditions, activation of mTORC1 supports cancer cells growth. In periods of cellular stress, low levels of amino acids or absent ATP induces mTORC1 inhibition, which subsequently activates a compensatory mechanism named autophagy [25]. Autophagy is a highly regulated pathway essential for cell survival in nutrient-deprived conditions, complementing the classical pathways like glycolysis. Autophagy supplies amino acids by inducing degradation of macromolecules and organelles in lysosome, thereby providing intracellular amino acids supply to fuel the TCA cycle, gluconeogenesis and protein synthesis [26]. However, the interplay between autophagy and glycolysis seems to be complex. Activation of autophagy has been observed to enhance glycolysis [27]. Deficiency of mitophagy can induce mitochondrial dysfunctions, enhancing glycolysis and Warburg effect [28]. Additionally, studies have found that oxidative stress induced by cancer cells can promote aerobic glycolysis and autophagy in cancer associated fibroblasts to obtain recycled nutrients from cancer associated fibroblasts. This phenomenon is called "Reverse Warburg Effect" [29]. Therefore, both the anabolic pathways, such as glycolysis, and the catabolic pathways, such as autophagy, interplay with each other, together contribute to cancer metabolism and supporting cellular growth. Taken together, abnormal alterations of multiple signaling pathways, transcription factors and metabolic pathways synergistically lead to metabolic reprogramming in cancer cells.

\section{Ubiquitination and deubiquitination}

Ubiquitination is an ATP-dependent cascade process ligating ubiquitin, a ubiquitously expressed protein consisting of 76 amino acids, to a substrate protein [30]. Ubiquitin-activating enzymes (E1s) initially bind to ubiquitin for activation, and then transfer activated ubiquitin to ubiquitin-conjugating enzymes (E2s). Ubiquitin ligases (E3s) finally transfer ubiquitin from E2 to substrates [30]. According to the number of ubiquitin attaching to one lysine residue in protein, ubiquitination is divided into monoubiquitination (single ubiquitin) and polyubiquitination (a chain of ubiquitin) [31]. In the polyubiquitination chain, ubiquitin can be attached via 7 lysine residues (K6, K11, K27, K29, K33, K48, and K63) or the first methionine (M1) [32]. Different types of ubiquitination lead to disparate fates of substrate proteins. K48-linked polyubiquitination is the most widely studied type, which mainly labels proteins for $26 \mathrm{~S}$ proteasomemediated recognition and degradation [32]. K48-linked polyubiquitination also has proteasome independent functions, including regulation of signaling events and 
transcription, which are possibly determined by the length of the ubiquitin chain [33-35]. K11-linked polyubiquitination is also associated with proteolysis [32]. Ubiquitin-proteasome system is involved in the degradation of more than $80 \%$ of proteins in cells [36]. K63-linked polyubiquitination is involved in signaling assemblies [32]. E3 ligases play a key role in the whole process of ubiquitination because of their specificity for substrates. In human genome, there are approximately 1000 E3 ligases, which can be divided into the homology to E6AP C terminus (HECT) domain-containing E3s, the RING-between-RING (RBR) family E3s and the really interesting new gene (RING) finger domain-containing E3s [37]. Deubiquitination is catalyzed by deubiquitinating enzymes (DUBs) to remove ubiquitin from ubiquitinated proteins, thus reversing the ubiquitination process [7]. About 100 DUBs fall into seven subgroups: the ubiquitin-specific proteases (USPs), the ubiquitin C-terminal hydrolases (UCHs), the ovarian tumor proteases (OTUs), the MachadoJosephin domain proteases (MJDs), the JAB1/MPN+/ MOV34 (JAMM) domain proteases, the monocyte chemotactic protein-induced proteins (MCPIPs), and the motif interacting with ubiquitin-containing DUB family (MINDY) [10]. Dynamic conversion between ubiquitination and deubiquitination is closely related to various cellular functions and thus, its dysregulation results in multiple disease, such as neurodegenerative diseases and cancer [38]. Understanding of ubiquitination and deubiquitination may provide novel insights into the treatment of these diseases.

\section{Ubiquitination and metabolic signaling pathways Ubiquitination of $\mathrm{mTOR}$}

Aberrant activation of mTORC1 is considered as a key feature of metabolic reprogramming. mTORC1 is a complex consisting of mTOR, Raptor, mLST8, PRAS40 and DEPTOR [39]. mTOR is an evolutionarily conserved serine/threonine protein kinase in the PI3K-related kinase superfamily, responsible for the catalytic activity of mTORC1 [40]. Translocation of mTORC1 to lysosome is the premise for its subsequent activation, identified as a critical step in the activation of mTORC1 signaling [41]. Activated RagA is thought to be the main participator in the re-localization of mTORC1 to the lysosomes in amino acid-stimulated cells [41]. Studies have found that E3 ligase TRAF6, which is upregulated in cancer cells, can mediate K63-linked polyubiquitination of mTOR by interacting with p62 under the stimulation of amino acids, promoting the translocation of mTORC1 to the lysosomes and subsequent activation (Fig. 1) [42]. In addition, decreased K48-linked ubiquitination of mTOR by E3 ligase FBX8 and FBXW7 alleviates proteasome-dependent degradation of mTOR, exerting an oncogenic effect in cancer as well $[43,44]$. Reduced mTOR ubiquitination is also linked to therapy resistance in cancer. Everolimus is a mTOR inhibitor used in breast cancer patients. Following downregulated phosphorylation of mTOR induced by depletion of dual specificity tyrosine-phosphorylation-regulated kinase 2 (DYRK2), ubiquitination and degradation of mTOR diminish, resulting in everolimus resistance [45]. Nonthermal plasma exerts anti-tumor effect by inducing RNF126 mediated K48-linked polyubiquitination and degradation of mTOR [46]. However, when faced with mitochondrial stress, E3 ligase PARKIN targets mTOR for ubiquitination, which maintains $\mathrm{mTORC} 1$ activity instead of affecting mTOR stability, thereby enhancing cell survival [47]. DUB USP9X can negatively modulate mTOR function and mTORC1 activity without changing mTOR protein level [48]. Therefore, different types of ubiquitination and deubiquitination play diverse roles in the regulation of mTOR function.

\section{Ubiquitination of raptor}

Raptor is the regulatory protein of mTORC1, maintaining the correct subcellular localization of $\mathrm{mTORC} 1$ and allowing the binding of mTORC1 with substrates [49]. DDB1-CUL4 E3 ligase complex is essential for maintaining mTORC1 stability by ubiquitinating Raptor. Displacement of DDB1-CUL4 complex by DUB UCH-L1 can remove K63-linked poly-ubiquitin chains on Raptor, bringing about reduced mTORC1 [49].

\section{Ubiquitination of $\mathrm{mLST} 8$}

mLST8, also called GßL, is a component of both mTORC1 and mTORC2. mLST8 is associated with the catalytic domain of mTOR and stabilizes its kinase activation loop [50]. mLST8 can be ubiquitinated by TRAF2 through K63-mediated linkage, which breaks the interaction between mLST8 and SIN1 in mTORC2, giving rise to elevated formation of mTORC1. This process can be reversed by DUB OTUD7B, leading to increased mTORC2 formation [50]. The study highlighted the role of ubiquitination and deubiquitination in the balance and competence between mTORC1 and mTORC2 signaling under various conditions.

\section{Ubiquitination of DEPTOR}

DEPTOR is an inhibitor of both mTORC1 and mTORC2. mTOR activation can phosphorylate DEPTOR and promote its recognition by $\mathrm{SCF}^{\beta-T r C P}$ ubiquitin ligase, targeting DEPTOR for polyubiquitination and proteolytic degradation [51, 52]. In tumors with isocitrate dehydrogenase1/2 (IDH1/2) mutations, oncometabolite 2-hydroxyglutarate indirectly promotes DEPTOR polyubiquitination by $\mathrm{SCF}^{\beta-\operatorname{TrCP}}$, thus activating $\mathrm{mTOR}$ [51]. E3 ligase RNF7 exerts oncogenic effect in prostate tumorigenesis by promoting ubiquitination and degradation of DEPTOR [53]. DUB OTUB1 specifically stabilizes DEPTOR via deubiquitination, thereby playing an 


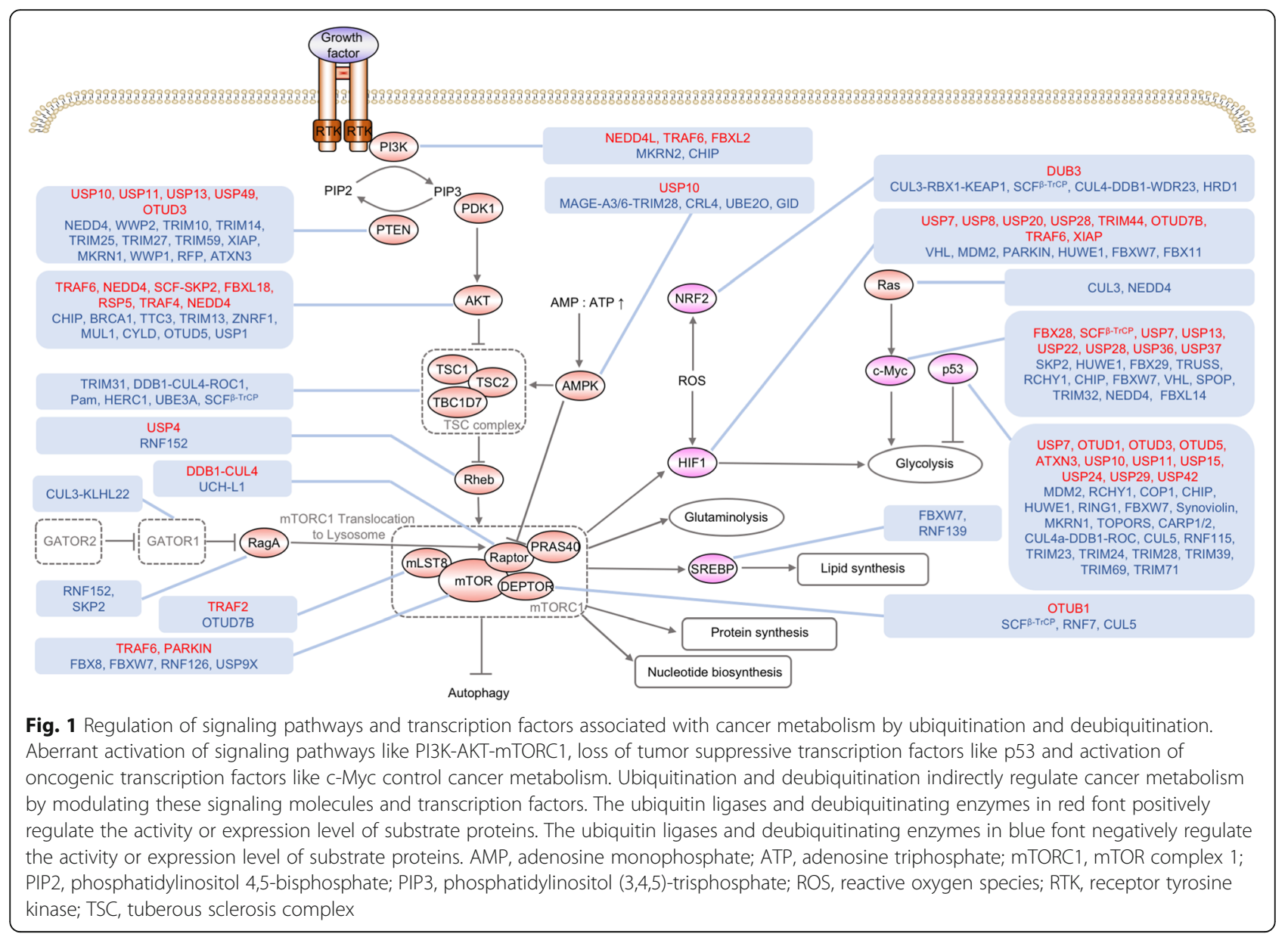

anticancer role [54]. CUL5 also targets DEPTOR for degradation, which is inhibited during autophagy activation [55]. Autophagy triggered by decreased ubiquitination and degradation of DEPTOR is related to drug resistance in cancer. Anticancer agent MLN4924 causes protective autophagy via inactivation of the CUL E3 ligase and accumulation of DEPTOR, which suppresses its effectiveness [56]. Enhancement of DEPTOR degradation can attenuate autophagy, which has been found to be an effective target in Temozolomide-resistant glioblastoma cells [57].

\section{Ubiquitination of RagA}

As we mentioned above, activated RagA plays a key role in the re-localization of mTORC1 to the lysosomes and subsequent activation of mTORC1 [41]. Study found that downregulation of lysosomal E3 ligase RNF152 protected cells from autophagy [58]. RNF152 modifies RagA by K63-linked polyubiquitination and promotes recruitment of RagA inhibitor GATOR1, thus inducing RagA inactivation. Then mTORC1 is released from the lysosomal surface, giving rise to blockade of mTORC1 signaling pathway [58]. Moreover, K63-linked polyubiquitination of RagA can also be mediated by E3 ligase SKP2, which exerts a similar effect with RNF152 [59].

\section{Ubiquitination of GATORs}

GATOR1 is a complex consisting of DEPDC5, NPRL2 and NPRL3, while GATOR2 consists of Mios, WDR24, WDR59, Seh1L and sec13. GATOR2 negatively regulates DEPDC5 in GATOR1, which acts as an inhibitor of RagA. Thus, GATOR2 exerts a promoting effect on RagA. Oncogenic E3 ligase CUL3-KLHL22 was observed to mediate K48-linked polyubiquitination of DEPDC5 and target DEPDC5 for degradation under the stimulation of amino acids and promote mTORC1 activation in tumor [60].

\section{Ubiquitination of Rheb}

GTP-bound Rheb is the activator of mTORC1 after translocation of mTORC1 to the lysosome. Monoubiquitination of Rheb by the lysosomal E3 ligase RNF152 can enhance its interaction with the tuberous sclerosis complex (TSC) complex, the major inhibitor of Rheb, and can decrease mTORC1 activation [61]. Following 
phosphorylation by AKT, USP4 can deubiquitinate Rheb to reverse the action of RNF152. Therefore, the dynamic change of ubiquitinating state of Rheb is associated with mTORC1 activation and tumor growth [61].

\section{Ubiquitination of TSC complex}

TSC complex, composed of TSC1, TSC2, and TBC1D7, is identified as a major upstream regulator of Rheb, converting GTP-bound Rheb to GDP-bound Rheb, thus inhibiting mTORC1 activation. TRIM31 mediated K48linked ubiquitination of TSC1-TSC2 complex induces its degradation and promotes growth of hepatocellular carcinoma cells [62]. FBXW5 recruits TSC2 protein to DDB1-CUL4-ROC1 E3 ligase complex, promoting its ubiquitination and degradation [63]. Moreover, E3 ligase Pam, HERC1 and UBE3A were also observed to mediate TSC2 protein ubiquitination and to enhance its degradation [64-66]. Interaction of TSC2 with TSC1 can prevent TSC2 from HERC1 ubiquitin ligase mediated degradation [66], while VPS34 can competitively bind to TSC1, resulting in TSC2 degradation [67]. E3 ubiquitin ligase $\mathrm{SCF}^{\beta-\mathrm{TrCP}}$ can ubiquitinate free TBC1D7 for degradation. Binding to TSC or AKT dependent phosphorylation of free TBC1D7 can prevent TBC1D7 from interaction with $\mathrm{SCF}^{\beta-\mathrm{TrCP}}$, stabilizing the pool of TBC1D7 [68].

\section{Ubiquitination of PI3K}

PI3K-mTORC1 signaling is the crucial signaling pathway that governs metabolic reprogramming and tumor cell growth. PI3K can be activated under the stimulation of growth factors. Activated PI3K phosphorylates PIP2, converting PIP2 to PIP3, which recruits 3-phosphoinositide-dependent protein kinase 1 (PDK1) and Akt to the membrane. PDK1 subsequently activates AKT, a negative regulator of TSC complex, and subsequently activating mTORC1 [69]. Activation of PI3K-mTORC1 signaling can exert various effects on metabolic process and play a key role in the regulation of tumor metabolism [69]. PI3K is a dimeric enzyme composed of a catalytic subunit $(\mathrm{p} 110 \alpha, \mathrm{p} 110 \beta$, or $\mathrm{p} 110 \gamma)$ and a regulatory subunit (p85 $\alpha, \mathrm{p} 85 \beta, \mathrm{p} 55 \alpha, \mathrm{p} 55 \gamma$, or $\mathrm{p} 50 \alpha$ ) [70]. A dynamic cycle of proteasome-dependent degradation and resynthesis of PI3Kp110 $\alpha$ were observed in activation of PI3K signaling. NEDD4L E3 ligase catalyzes free PI3Kp110 $\alpha$ for ubiquitination, leading to its proteasome-dependent degradation and maintenance of PI3K signaling [70]. TRAF6 E3 ligase promotes activation of PI3K pathway in cancer by nonproteolytic polyubiquitination of PI3K catalytic subunit $\mathrm{p} 110 \alpha$ [70]. TRAF6 also directs PI3K recruitment to TGF- $\beta$ receptor via K63-linked polyubiquitination of PI3Kp85 $\alpha$, which is essential for TGF- $\beta$-induced activation of PI3K signaling [71]. What's more, PI3K regulatory subunit p85 $\alpha$ can be ubiquitinated by E3 ligase MKRN2 and E3 ligase complex HSP70-CHIP through K48-mediated linkage, bringing about proteolysis of PI3Kp $85 \alpha$ and downregulation of PI3K signaling in cancer [72, 73]. Dephosphorylated free p85 $\beta$ is ubiquitinated by FBXL2 for proteolysis. Decreased free p $85 \beta$ reduces its competition with p 85 -p110 heterodimers for docking sites on cell membrane, thus upregulating PI3K signaling [74]. Therefore, both the catalytic subunit and the regulatory subunit can be ubiquitinated, exerting various effects on PI3K signaling.

\section{Ubiquitination of PDK1}

PDK1 phosphorylates and activates AKT, transducing signal from activated PI3K to AKT. Attenuated ubiquitination and degradation of PDK1 are related to chemoresistance in ovarian cancer [75]. Monoubiquitination of PDK1 in cancer cell lines can be reversed by USP4 catalyzation, the function of which still remains unclear [76].

\section{Ubiquitination of AKT}

AKT, a negative regulator of TSC complex, can be activated by PI3K signaling, exerting oncogenic effect by promoting mTORC1 signaling. K63-linked polyubiquitination of AKT catalyzed by TRAF6, NEDD4, SCF-SKP2, FBXL18, RSP5 or TRAF4 E3 ligase is required for cell membrane localization of AKT and is essential in activation of PI3K-AKT-mTOR pathway and subsequent upregulation of glycolysis [77-82]. SETDB1 catalyzed methylation of AKT enhances its K63-linked ubiquitination and activation [83]. After interaction with KDM4B, TRAF6 promotes its ubiquitination of AKT in colorectal cancer, facilitating glucose metabolism and tumor growth [84]. DUB CYLD, OTUD5 and USP1 can reverse K63-linked polyubiquitination of AKT and inhibit its activation [85-87]. Bisdemethoxycurcumin can inhibit hepatocellular carcinoma cell growth by promoting CYLDmediated deubiquitination of AKT [88]. Enhanced AKT ubiquitination and activation caused by downregulation of DUB OTUD5 give rise to radioresistance in cervical cancer [86]. pAKT ubiquitinated by NEDD4 can regulate its nuclear trafficking to promote tumorigenesis [79]. What's more, E3 ligases CHIP, BRCA1, TTC3, TRIM13, ZNRF1, MUL1 can modify AKT by K48-linked ubiquitination and promote degradation of AKT to suppress its activation [89-94]. Anticancer agents Rhus coriaria, SC66 and Vitamin C can stimulate ubiquitination and degradation of AKT in cancer cells $[95,96]$. When proteasome impairs in cellular stress, E3 ligase MUL1 catalyzes K48-linked ubiquitination of AKT, which subsequently undergoes lysosomal degradation, playing 
key roles in cellular survival [97]. This process can be reversed by DUB USP7 [97].

\section{Ubiquitination of PTEN}

As a negative regulator of PI3K/AKT signaling pathway, phosphatase and tensin homolog (PTEN) converts PIP3 back to PIP2, playing tumor suppressive functions in various cancers. Identified as the E3-ligase of PTEN, NEDD4 not only contributes to monoubiquitination of PTEN for its nuclear transport but also mediates polyubiquitination of PTEN for its proteasomal degradation to activate AKT signaling transduction [98]. Upregulation of LINC00152 enhances NEDD4 mediated ubiquitination and degradation of PTEN in breast cancer [99]. E3 ligase WWP2, TRIM10, TRIM14, TRIM25, TRIM27, TRIM59 and XIAP can target PTEN for ubiquitination and degradation as well [100-106]. AKT activated MKRN1 E3 ligase also mediates ubiquitination and degradation of PTEN, thus positively regulating PI3K/AKT signaling axis [107]. The E3 ligase WWP1 mediated polyubiquitination can suppress the membrane recruitment and function of PTEN [108]. Ubiquitination via E3 ligase RFP can downregulate PTEN phosphatase activity rather than altering its stability or localization [109]. As for the deubiquitination of PTEN, USP10, USP11, USP13, USP49, and OTUD3 catalyze removal of K48-linked ubiquitin chain on PTEN to enhance protein stability of PTEN and attenuate AKT signaling pathway [110-114]. USP7-induced deubiquitination of PTEN results in its nuclear exclusion rather than regulating its protein stability $[115,116]$. DUB ATXN3 suppress PTEN expression by reducing its transcription rather than altering its protein level [117].

\section{Ubiquitination of AMPK}

AMPK is an inhibitor of mTORC1 by phosphorylating Raptor and activating TSC2. As an energy sensor, AMPK is crucial in maintenance of NADPH and ATP level in response to reduced intracellular ATP. AMPK is composed of catalytic $\alpha$ and regulatory $\beta$ and $\gamma$ subunits [118]. E3 ligase complex MAGE-A3/6-TRIM28 and E3 ligase CRL4A catalyze ubiquitination of AMPK $\alpha$ and target it for degradation, thus reducing autophagy and altering cancer metabolism $[118,119]$. UBE2O, an atypical ubiquitin enzyme with both E2 and E3 activities, ubiquitinates AMPK $\alpha 2$ for degradation [120]. CRL4 catalyzed ubiquitination also directs AMPK $\gamma$ proteolysis [121]. GID ubiquitin ligase mediates ubiquitination and degradation of AMPK as well, leading to decreased autophagy and increased mTOR activity [122]. Ubiquitination of AMPK $\alpha$ can be reversed by USP10 to remove the ubiquitin chain from AMPK $\alpha$ and promote AMPK activation [122].

\section{Ubiquitination of KRAS}

As a common mutated oncogene driving tumorigenicity in pancreatic, colon and lung cancers, KRAS enhances expression of glucose transporter type 1 (GLUT1) and controls glycolysis and glutamine metabolism in cancer cells, which is considered to be associated with metabolic reprogramming in primary invasive cancers [123]. Monoubiquitination and diubiquitination of KRAS elevate its GTP loading ability [124]. CUL3-based E3 ligase complex can mediate polyubiquitination and degradation of KRAS [125]. KRAS4B, an alternative splicing of KRAS gene, is targeted by E3 ligase NEDD4 for ubiquitination and proteolysis. However, activated KRAS signaling upregulates NEDD4 expression and prevents NEDD4-mediated KRAS ubiquitination. This in return promotes NEDD4 catalyzed degradation of PTEN to trigger tumor growth [126]. Therefore, modification of signaling molecules by ubiquitination can exert various effects in signaling pathways, thereby regulating metabolic reprogramming in cancer cells.

\section{Ubiquitination and transcription factors Ubiquitination of HIF-1}

HIF-1 is a metabolic-associated transcription factor which can be activated by mTORC1, accumulation of ROS and accumulation of TCA cycle metabolites. Activation of HIF-1 enhances expression of various glycolytic genes including hexokinase 1 (HK1), HK2, LDHA, and pyruvate dehydrogenase kinase isoform1 (PDK1), strengthening glycolytic flux and maintaining redox homeostasis [127]. HIF-1 consists of $\alpha$ and $\beta$ subunits. Compared with HIF-1 $\beta$, HIF- $1 \alpha$ is unstable and susceptible to ubiquitination. E3 ligase VHL can mediate degradation of HIF- $1 \alpha$ under normoxic conditions. Loss of VHL in cancer cells stabilizes HIF- $1 \alpha$, contributing to aerobic glycolysis [128, 129]. E3 ligase MDM2, PARKIN and HUWE1 can catalyze ubiquitination of HIF- $1 \alpha$ and targets it for degradation, thus exerting an anti-tumor effect [130-132]. Tumor suppressors PTEN and p53 can enhance MDM2-mediated ubiquitination and degradation of HIF-1 $\alpha$ to inhibit tumorigenesis [133-135]. Following phosphorylation by GSK3 $\beta$, HIF- $1 \alpha$ ubiquitination via FBXW7 is increased, which promotes proteolysis of HIF-1 $\alpha$ and inhibits tumor growth [136]. Anticancer drug glyceollins and thymoquinone can inhibit tumor growth by elevating ubiquitination and degradation of HIF-1 $\alpha$ [137, 138]. E3 ligase FBX11 can reduce the mRNA stability rather than protein stability of HIF- $1 \alpha$ [139]. DUB USP28 can antagonize the ubiquitination of HIF- $1 \alpha$ by FBXW7 [136]. TRIM44, USP20 and USP7 also stabilizes HIF- $1 \alpha$ by deubiquitination, leading to tumor progression under hypoxia [140-143]. DUB OTUD7B can suppress degradation of HIF- $1 \alpha$ via proteasome-independent manner [144]. USP8 mediated 
deubiquitination of HIF-1 $\alpha$ was to maintain its expression level in normal conditions [145]. K63-linked polyubiquitination of HIF- $1 \alpha$ catalyzed by TRAF6 can protect it from degradation [146]. XIAP modifies HIF- $1 \alpha$ by K63-linked polyubiquitination to promote its nuclear retention and enhance HIF-dependent gene expression [147]. In conclusion, ubiquitination is an important regulatory mechanism of HIF-1.

\section{Ubiquitination of c-Myc}

Transcription factor c-Myc contributes to metabolic reprogramming through transcriptional regulation of genes participating in metabolism, such as LDHA [148]. c-Myc is an unstable protein susceptible to ubiquitination and proteolysis. E3 ligase SKP2, HUWE1, FBX29, TRUSS, RCHY1, CHIP, FBXW7, VHL, SPOP, TRIM32, NEDD4 and FBXL14 can target c-Myc for ubiquitination and degradation [149-160]. Decreased ubiquitination of c-Myc by VHL is observed to drive aerobic glycolysis in breast cancer cells [159]. Mutation or deletion of these E3 ligase genes induces carcinogenesis by attenuating cMyc degradation. Anticancer drugs, including lanatoside C, diminish cancer cell growth by upregulating ubiquitination and degradation of c-Myc in cancer [161-163]. Ubiquitination of c-Myc can also be regulated by interaction with other molecules. FBXL16 can competitively bind with $\mathrm{c}-\mathrm{Myc}$ without inducing ubiquitination of cMyc, thereby rescuing c-Myc from FBXW7-mediated degradation [164]. Interaction with Evi5 also antagonizes FBXW7-mediated ubiquitination of c-Myc protein in laryngeal squamous cell carcinoma [165]. Phosphorylated ANXA2 interacts with MYC and inhibits ubiquitindependent proteasomal degradation of MYC protein in esophageal cancer [166]. LncRNA XLOC_006390, GLCC1 and LINC01638 also block ubiquitination of c-Myc [156, 167, 168]. What's more, E3 ligase FBX28 mediated nonproteolytic ubiquitination of c-Myc can enhance c-Myc dependent transcription [169]. Ubiquitination of c-Myc by E3 ligase $\mathrm{SCF}^{\beta-\operatorname{TrCP}}$ in $\mathrm{G} 2$ phase can stabilize c-Myc to facilitate recovery from an S-phase arrest [170]. Moreover, the DUB USP7, USP13, USP22, USP28, USP36 and USP37 stabilize c-Myc, thereby stimulating tumor growth $[155,157,171-174]$.

\section{Ubiquitination of $\mathrm{p} 53$}

As a critical tumor suppressor participating in cell cycle regulation and apoptosis, p53 was also clarified by recent studies of its participation in metabolic reprogramming. Loss of p53 induces enhancement of glycolysis and maintenance of redox homeostasis in cancer cells [175]. Monoubiquitination, K48-linked and K63-linked polyubiquitination were observed to be common posttranslational modification of p53 protein. MDM2/ MDMX complex is the major E3 ligases and the main negative regulator of p53, degrading p53 and decreasing transcription of p53 target genes [176]. At the same time, MDM2 is targeted by p53 to form a negative feedback loop for the dynamic regulation of p53 under stressed and unstressed conditions [177]. RCHY1, COP1, CHIP, HUWE1, RING1, FBXW7, Synoviolin, MKRN1, TOPORS, CARP1/2, CUL4a-DDB1-ROC, CUL5, RNF115, TRIM23, TRIM24, TRIM28, TRIM39, TRIM69, TRIM71 can also target p53 for K48-linked polyubiquitination and degradation [178-185]. K48linked polyubiquitination of p53 can be regulated by various molecules. For instance, MAVS and ATF3 can stabilize p53 by preventing p53 from MDM2-mediated ubiquitination [186, 187]. ACP5 mediated p53 phosphorylation enhanced the ubiquitination and degradation of p53 [188]. p53 protein can be deubiquitinated by DUB OTUD1, OTUD3, OTUD5, ATXN3, USP10, USP11, USP15, USP24, USP29 and USP42 to enhance its function as tumor suppressor under the conditions of high carcinogenicity and genotoxicity [117, 189-198]. DUB USP7 can catalyze deubiquitination of p53 and upregulate level of p53 protein as well [199]. On the other hand, USP7 mediates deubiquitination and stabilization of MDM2 and MDMX, the major E3 ligase of p53 protein, thereby reducing the protein level of p53 [200, 201]. Studies have found that the binding of USP7 with MDM2 is much stronger than that with p53 [200]. USP7 is highly expressed in most cancers, such as breast cancer and colorectal cancer, and plays carcinogenic role by deubiquitinating MDM2 and MDMX [202, 203]. Application of USP7 inhibitors can activate the p53 signaling in cancer cells and play anti-cancer functions [204]. However, USP7 is downregulated in some tumors, such as pulmonary adenocarcinoma, and plays a tumor suppressive role in p53-dependent mechanism [205]. Therefore, USP7 acts in a content-dependent manner and has a paradoxical action on p53 according to different tissues. What's more, CUL7-mediated K63-linked polyubiquitination of p53 and MDM2 or MSL2-mediated monoubiquitination of p53 are associated with its translocation to the cytoplasm [206]. Anticancer drug HLI98 inhibits p53 degradation via MDM2 to enhance its tumor suppressive function [207]. Therefore, it's likely for p53 ubiquitination regulation to act as an effective therapeutic method for cancers.

\section{Ubiquitination of NRF2}

Accumulation of ROS can also activate NRF2, another essential transcriptional factor for the maintenance of redox homeostasis. KEAP1, a substrate-specific adapter of a CUL3-RBX1 E3 ligase complex, is the binding partner of NRF2 and it negatively controls NRF2 stability. Under normal conditions, the CUL3-RBX1 mediates ubiquitination and degradation of NRF2. Electrophile 
metabolites formed in oxidative stress prevents CUL3RBX1-KEAP1 complex from ubiquitinating NRF2, thereby stabilizing NRF2. NRF2 subsequently activates transcription of antioxidant proteins, such as GPXs and TXNs as well as enzymes involved in glutathione and NADPH synthesis [208]. p62, RMP and CDK20 can competitively bind with KEAP1 [209-211]. TRIM25 targets KEAP1 for ubiquitination and degradation [212]. DUB USP15 can stabilize KEAP1 [212]. These events will change the level of NRF2 and affect the transcriptional activity of NRF2 targeted genes. In non-small cell lung cancer, phosphorylation by BMP8A or interaction with PAQR4 can prevent ubiquitination of NRF2 by KEAP1 and stabilize NRF2, resulting in chemotherapy resistance [213, 214]. Besides CUL3-RBX1-KEAP1 complex, E3 ligase $\mathrm{SCF}^{\beta-T r C P}$, CUL4-DDB1-WDR23, HRD1 can also ubiquitinate NRF2 and regulate its stability [215-217]. DUB DUB3 removes ubiquitin chain on NRF2 and stabilize NRF2, leading to chemoresistance in colorectal cancer [218].

\section{Ubiquitination of SREBP1}

SREBP1 is a transcription factor associated with lipogenic genes [219]. mTORC1 signaling induces enhanced activity of SREBP1 to meet the requirements for fatty acid in proliferating cancer cells [220]. Activation of SREBP1 upregulates fatty acid synthesis as well as lipid import from extracellular space [220]. After phosphorylated by GSK-3, SREBP1 is prone to ubiquitination by E3 ligase FBXW7 and degradation via the ubiquitin-proteasome system [221, 222]. Deacetylation of SREBP by SIRT1 also enhances its ubiquitination and proteolysis [223]. RNF139 can ubiquitinate precursor forms of SREBP1, thereby preventing SREBP1 synthesis [224].

\section{Ubiquitination and autophagy Ubiquitination of ULK1}

In nutrient-deprived conditions, inhibition of mTORC1 subsequently activates autophagy, a highly regulated pathway essential for cell survival [25]. Autophagy complements amino acids by inducing degradation of macromolecules and organelles in lysosomes [26]. ULK1 complex, composed of the ULK1, ATG13 and FIP200, is directly regulated by mTORC1 and is required for autophagy induction. TRAF6 catalyzed K63-linked polyubiquitination of ULK1 can stabilize ULK1 to promote activation of autophagy, which is related to drug resistance in chronic myeloid leukemia patients [225]. Activating molecule in BECN1-regulated autophagy protein 1 (AMBRA1) is a cofactor that interacts with Beclin-1 to regulate autophagy. Decreased phosphorylation of AMBRA1 caused by mTORC1 inactivation will promote its interaction with TRAF6 to upregulate polyubiquitination of ULK1, thereby potentiating autophagy initiation [226]. TRIM16 and TRIM32 also target ULK1 for K63-linked polyubiquitination, which stabilizes ULK1 and increases its phosphorylating activity, respectively [227, 228]. DUB USP1 hydrolyzes the K63-linked ubiquitin chain on ULK1 [229]. Downregulation of USP24 also enhances ULK1 ubiquitination, thereby increasing protein stability and kinase activity of ULK1 [230]. These studies indicate the shift between ubiquitinated ULK1 and deubiquitinated ULK1 is essential for autophagy initiation.

Ubiquitination was also observed to be essential in the regulation of autophagy threshold during autophagy progression. NEDD4L-mediated ULK1 ubiquitination via K27 and K29-linkage assembly induces its proteolysis [231]. Decreased level of ULK1 activates transcription of ULK1 to maintain its basal protein level. Newly synthesized ULK1 will be deactivated by mTOR to ensure a safe threshold of autophagy [231]. CUL3-KLHL20 complex can also downregulate autophagy by targeting activated ULK1 for ubiquitination and proteolysis [232]. ULK1 can be deubiquitinated by USP20, which prevents it from degradation, maintaining its basal level required for the initiation of autophagy [233]. In prolonged starvation, the interaction between USP20 and ULK1 reduces to terminate autophagy [233]. In conclusion, ubiquitination and deubiquitination play essential functions in both autophagy initiation and autophagy progression. Modulating ubiquitination might be an effective treatment for chemoresistant patients with enhanced autophagy in cancer cells.

\section{Ubiquitination of class III PI3K complex}

Class III PI3K complex is composed of Beclin-1, ATG14, VPS34 and AMBRA1, essential for the nucleation of the phagophore. Various factors interact with Beclin-1 to regulate autophagy signaling. BCL2 can suppress autophagy by inhibiting Beclin-1 [234]. Starvation induced K63-linked ubiquitination of Beclin-1 by TRAF6 or AMBRA1 can block its interaction with BCL2, thus activating autophagy $[235,236]$. AMBRA1 targeted polyubiquitination of Beclin-1 can enhance its association with VPS34 to activate of VPS34 [236]. TRIM50 mediated K63-linked polyubiquitination of Beclin-1 promotes its activation by ULK1 and induces autophagy in starvation [237]. DUB A20 and USP14 limit autophagy by reversing K63-linked ubiquitination of Beclin-1 [235, 238]. NEDD4 and RNF216 ubiquitinate Beclin-1 through K11- and K48- mediated linkage, respectively, which promote its degradation [239, 240]. DUB including USP19, ATXN3, USP10 and USP13 can reverse K11- or K48ubiquitination of Beclin-1 to rescue it from degradation [241-243]. Beclin-1 also increases deubiquitinating 
activities of USP10 and USP13, further enhancing autophagy by positive feedback [241].

FBXL20 mediates ubiquitination and proteasome degradation of VPS34 to inhibit autophagy [244]. ATG14 was observed to be ubiquitinated by ZBTB16-CUL3ROC1 E3 ubiquitin ligase complex for degradation [245].

AMBRA1 is degraded via the action of E3 ligase CUL4 under normal conditions. Activation of ULK1 disassociates CUL4 from AMBRA1, causing stabilization of AMBRA1 to promote autophagy. Disassociation of AMBRA1 with CUL4 can promote AMBRA1 binding to CUL5 to inhibit CUL5-mediated DEPTOR degradation, thereby inducing autophagy [55]. CUL4 can re-associate with AMBRA1 to promote its proteolysis when autophagy terminates, thus regulating autophagy response [55]. What's more, E3 ligase RNF2 can also catalyze K48linked ubiquitination and proteolysis of AMBRA1, thus downregulating autophagy [246]. Therefore, all the components of the Class III PI3K complex can be regulated by ubiquitination, which exerts important effects on autophagy.

\section{Ubiquitination of WIPI2}

WIPI2 is involved in an early step of the formation of preautophagosomal structures. mTORC1 can mediate phosphorylation of WIPI2. E3 ligase HUWE1 interacts with phosphorylated WIPI2 and catalyzes ubiquitination of phosphorylated WIPI2, which is subsequently targeted for proteolysis, thus inhibiting autophagy flux [247].

\section{Ubiquitination of ATG4}

ATG4 contributes to LC3 processing, playing an essential role in the phagophore expansion and autophagosome completion. E3 ligase RNF5 targets ubiquitination and degradation of ATG4B, thus limiting autophagy flux. When cell starves, RNF5 de-associates with ATG4B to induce autophagy [248].

\section{Ubiquitination and metabolic enzymes Ubiquitination and glucose metabolism}

Increased glucose uptake and enhanced glycolytic flux are metabolic characteristics of cancer cells, supplying subsidiary pathways to provide precursors for macromolecule synthesis. Activated AKT was observed to inhibit ubiquitination of $\mathrm{HK} 1$, the first rate-limiting enzyme in the glucose metabolism pathway, promoting glycolysis and glioblastoma progression [249]. HUWE1 mediated K63-linked ubiquitination of HK2 promotes its re-localization and activation, enhancing glycolysis and tumor growth (Fig. 2) [250]. TRAF6 mediated K63linked ubiquitination of HK2 directs HK2 degradation by autophagy, thereby negatively regulating glycolysis [251]. Deubiquitination of HK2 catalyzed by CSN5 can rescue it from degradation and enhance glycolytic flux during hepatocellular cancer metastasis [252]. Mitochondrial HK can also be ubiquitinated by PARKIN, inducing its proteasomal degradation [253].

Phosphofructokinase (PFK), the second rate-limiting enzyme in glycolysis, is a key regulator of glycolytic flux in cancer cells. Decreased A20 mediated ubiquitination and degradation of PFK liver type (PFKL) are related to increased glycolysis during hepatocellular carcinoma progression [254]. Phosphorylation of PFK1 platelet isoform (PFKP) by AKT can prevent it from TRIM21mediated ubiquitination and degradation, promoting aerobic glycolysis in glioblastoma cells [255].

Pyruvate kinase M2 (PKM2) is the third rate-limiting enzyme of glycolysis. Decreased CHIP catalyzed ubiquitination and degradation of PKM2 are associated with Warburg effect in ovarian cancer cells [256]. Downregulated ubiquitination of PKM2 by TRIM58 is related to progression of osteosarcoma [257]. E3 ligase PARKIN modifies PKM2 by ubiquitination to decrease its enzymatic activity without affecting its stability [258]. PKM2 deubiquitinated by USP7 can strengthen the protein stability of PKM2 [259]. USP20 can also hydrolyze the ubiquitin chain on PKM2, but the detailed function of this deubiquitination is unclear [260].

Other enzymes in glucose metabolism can be also modified by ubiquitination. Glucose-6-phosphate isomerase (GPI), which catalyzes the conversion of glucose-6phosphate to fructose-6-phosphate, can be ubiquitinated and degraded by E3 ligase RNF45 and TRIM25 [261]. 6phosphofructo-2-kinase/fructose-2,6-bisphosphatase 3 (PFKFB3) is a glycolysis-promoting enzyme catalyzing the conversion between fructose 2,6-bisphosphate and fructose 6-phosphate. ROCK2 interacts with PFKFB3 and attenuates its ubiquitination and degradation in osteosarcoma cells [262]. What's more, glycolysis during different stages of cell cycle in Hela cells is regulated by E3 ligases. Decreased E3 ligase APC/C-CDH1 can attenuate proteasomal degradation of PFKFB3, promoting glycolysis and transition of late G1 phase into S phase. E3 ligase $\mathrm{SCF}^{\beta-\operatorname{TrCP}}$ activated during $\mathrm{S}$ phase can target PFKFB3 for degradation [263]. Similarly, decreased ubiquitination and increased stability of glutaminase 1 (GLS1) were also observed to be mediated by decreased APC/C-CDH1 in mid-to-late G1 [264]. Phosphoglycerate kinase 1 (PGK1) catalyzes the conversion of 1,3diphosphoglycerate to 3-phosphoglycerate. Decreased ubiquitination of PGK1 leads to chemotherapy resistance in gallbladder cancer cells [265]. Interaction between MetaLnc9 and PGK1 blocks ubiquitin-mediated degradation of PGK1, promoting lung cancer metastasis [266]. Following phosphorylation, phosphoglycerate mutase (PGAM), which converts 3-phosphoglycerate to 2phosphoglycerate, can be ubiquitinated by MDM2 for degradation [267]. Decreased ubiquitination of PGAM 


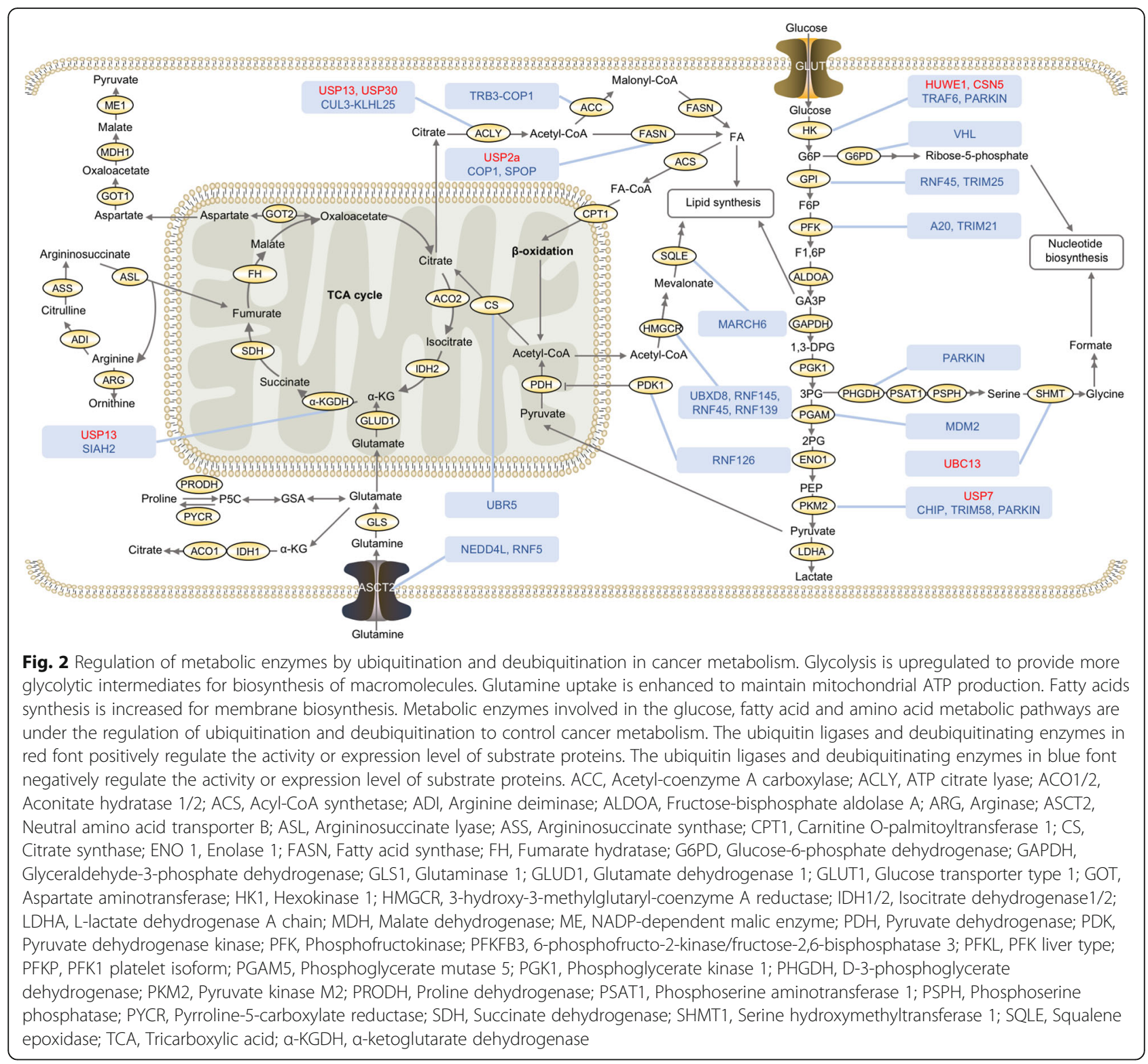

by MDM2 contributes to neoplastic transformation [267]. PDK can be ubiquitinated by RNF126, which targets them for proteasomal degradation, enhancing conversion of pyruvate to acetyl-CoA by pyruvate dehydrogenase (PDH) in cancer cells [268].

Ubiquitination of enzymes involved in the TCA cycle is also associated with cancer progression. Decreased UBR5-mediated ubiquitination of citrate synthase leads to citrate accumulation in hypoxia breast cancer cells, promoting cell migration, invasion, and metastasis [269]. HIF-1 activation under hypoxia condition can promote $\alpha$-ketoglutarate dehydrogenase $(\alpha-\mathrm{KGDH})$ complex ubiquitination and proteolysis by SIAH2. Decreased $\alpha-$ KGDH activity inhibits glutamine oxidation and promotes glutamine-dependent lipid synthesis for tumor growth [270]. USP13 promotes ovarian cancer progression by deubiquitinating and upregulating $\alpha-\mathrm{KGDH}$ [271].

Glucose-6-phosphate dehydrogenase (G6PD) catalyzes the oxidative pentose phosphate pathway, an essential process producing ribose-5-phosphate and NAPDH from G6P. G6PD was observed to be ubiquitinated and degraded by VHL E3 ubiquitin ligase in podocytes [272]. VHL is tumor-suppressor protein [273]. But whether this regulation exists in cancer cells is unclear. Fructose1,6-biphosphatase (FBP1) is a rate-limiting enzyme of gluconeogenesis. MAGE-TRIM28 mediated ubiquitination and degradation of FBP1 in hepatocellular carcinoma promotes Warburg effect and cancer progression [274]. Phosphoenolpyruvate carboxykinase 1 (PEPCK1) 
is another rate-limiting enzyme in gluconeogenesis. High glucose in diabetes stimulates PEPCK1 acetylation, which promotes UBR5 mediated ubiquitination and degradation of PEPCK1 [275]. Studies have found that GLUT1 can be ubiquitinated for degradation in diabetes [276]. E3 ubiquitin ligase Malin mediated ubiquitination of glycogen debranching enzyme (AGL) is associated with Lafora and Cori's disease [277]. But whether ubiquitination of GLUT1, PEPCK1 and AGL participates in tumor progression is still unknown. What's more, ubiquitination and deubiquitination of other cancer associated metabolic enzymes is still unknown, such as enolase in glycolysis, isocitrate dehydrogenase in the TCA cycle, glycogen phosphorylase in glycogen metabolic process, and pyruvate carboxylase in gluconeogenesis. The relationship between their specific E3 ligases and DUBs and oncogenesis still need exploration.

\section{Ubiquitination and fatty acid metabolism}

Fatty acids synthesis is necessary for membrane biosynthesis in proliferating tumor cells. CUL3-KLHL25 E3 ligase can inhibit lipid synthesis and tumor growth by targeting ATP citrate lyase (ACLY) for ubiquitination and proteolysis [278]. However, USP13 and USP30 can mediate deubiquitination of ACLY, increasing the stability of ACLY to promote development of ovarian cancer and hepatocellular carcinoma, respectively [271, 279]. TRB3-COP1 mediates proteolysis of acetyl-coenzyme A carboxylase (ACC) in ubiquitin-dependent manner, inhibiting fatty acid synthesis and stimulating lipolysis [280]. But in breast cancer cells, ACC-alpha (ACCA) interacts with AKR1B10, which prevents ACCA from ubiquitination and proteolysis, thereby promoting de novo fatty acid synthesis and enhancing tumor growth [281]. E3 ligase COP1 can ubiquitinate fatty acid synthase (FASN) with SHP2 as an adapter [282]. E3 ligase SPOP mutation, which is common in prostate cancer, inhibits its ubiquitination of FASN. Increased FASN triggers lipid accumulation and promotes prostate cancer progression [283]. AKT activation promotes deubiquitination of FASN by the USP2a and increased lipogenesis, which promotes hepatocarcinogenesis [284, 285].

3-hydroxy-3-methylglutaryl-coenzyme A reductase (HMGCR) is a rate-limiting enzyme in cholesterol biosynthesis. E3 ligases UBXD, RNF145 and RNF45 can mediate sterol-induced ubiquitination and degradation of HMGCR, attenuating cholesterol biosynthesis [286288]. Hypoxia triggered upregulation of insulin-induced gene 2 can interact with HMGCR and promote its ubiquitination and degradation to avoid unnecessary oxygen consumption [289]. Dysregulated cholesterol metabolism is observed in multidrug resistant cancer cells (MDR), in which decreased E3 ligase RNF139 upregulates HMGCR and induces enhanced cholesterol synthesis [290].
Squalene epoxidase (SQLE), which catalyzes the first oxygenation reaction of cholesterol biosynthesis, can be ubiquitinated and degraded by E3 ligase MARCH6 under stimulation of sterol [291]. Additionally, E3 ligase MYLIP can modulate cellular cholesterol uptake by ubiquitinating LDL receptor which is responsible for cholesterol import [292]. But whether ubiquitination of SQLE and LDL receptor participate in cancer progression is unknown. In addition, ubiquitination and deubiquitination of other enzymes participating in fatty acid metabolism, such as Carnitine O-palmitoyltransferase 1 (CPT1), and their relationship with cancer progression have not been studied yet.

\section{Ubiquitination and amino acid metabolism}

In cancer cells, glutamine serves as another important carbon source for the TCA cycle to sustain mitochondrial ATP production [1]. Glutamine uptake increases dramatically in cancer cells. NEDD4L-depleted cancer cells have enhanced neutral amino acid transporter B (ASCT2) stability and glutamine uptake to fuel the mitochondrial metabolism [293]. Promotion of RNF5targeted ubiquitination and degradation of glutamine carrier proteins ASCT2 and SLC38A2 can improve responsiveness of breast cancer cells to Paclitaxel treatment [294]. Glutamine can be converted via GLS to glutamate, which can subsequently be converted to $\alpha$ ketoglutarate to fuel the TCA cycle. Succinylation of GLS suppresses its K48-linked ubiquitination and degradation, stabilizing GLS and promoting glutaminolysis in cancer cells [295]. Study also found the function of supranutritional dose of selenite in suppressing tumor progression by promoting APC/C-CDH1 mediated GLS1 ubiquitination and degradation [296]. Ubiquitination of other enzymes involved in glutamine metabolism, such as glutamate dehydrogenase 1 (GLUD1), hasn't been studied.

3-phosphoglycerate, an intermediate product of glycolysis, can be converted to serine by D-3phosphoglycerate dehydrogenase (PHGDH). This conversion is subsequently associated with formate production for nucleotide synthesis. Downregulated PARKIN in cancer suppresses ubiquitination of PHGDH and enhances its stability and protein level, thereby activating serine synthesis and promoting cancer progression [297]. Serine hydroxymethyltransferase 1 (SHMT1) is involved in the conversion of serine to glycine. K48-linked ubiquitination of SHMT1 mediates its degradation in the cytoplasm. K63-linked ubiquitination of SHMT1 by $\mathrm{UBC} 13$ in the nucleus promotes its nuclear export and prevents it from degradation, promoting tumor progression [298]. What's more, dysregulation of aspartate and arginine metabolism is also associated with cancer progression [299]. However, ubiquitination and 
deubiquitination of the enzymes participating in aspartate and arginine metabolism haven't been studied and are worth attention in the future.

\section{Conclusions}

In the past decades, extensive efforts have been made to clarify the molecular mechanisms associated with metabolic reprogramming in cancer. In this review, we highlight the roles of ubiquitination and deubiquitination as modulators of cancer metabolism. Facing metabolic stresses, such as hypoxia, ubiquitination and deubiquitination in cancer cells can be abnormally regulated [10, 270]. On the other hand, dysregulated ubiquitination and deubiquitination play nonnegligible roles in cancer metabolism by involving in the regulation of metabolic reprogramming related signaling pathways, transcription factors as well as metabolic enzymes. For instance, hypoxia induces E3 ubiquitin ligase SIAH2 mediated ubiquitination and proteolysis of $\alpha-\mathrm{KGDH}$, inhibiting glutamine oxidation and promoting glutaminedependent lipid synthesis to promote tumor growth [270]. Therefore, the interactions between ubiquitination/deubiquitination and cancer metabolism are complex and require more studies. Most studies have focused on the involvement of ubiquitination and deubiquitination in the regulation of signaling pathways and transcription factors, while ubiquitination and deubiquitination of the enzymes involved in glucose, fatty acid and amino acid metabolism are worth more attention in the future.

In the regulation of cancer metabolism and tumor progression, the E3 ubiquitin ligases/DUBs-substrates network is of high complexity. Single E3 ubiquitin ligase or DUB can target numerous substrates, and one molecule can be regulated by multiple E3 ubiquitin ligases or DUBs. For example, FBXW7 acts as a tumor suppressor by targeting mTOR, HIF- $1 \alpha, \mathrm{c}-\mathrm{Myc}$ and SREBP1 for degradation [43, 136, 160, 222]. However, when facing DNA damage, elevated FBXW7 mediates proteasomal degradation of $\mathrm{p} 53$, leading to radiotherapy resistance [300]. Amino acids can stimulate subcellular localization of TRAF6 to lysosomes for subsequent K63-linked polyubiquitination and activation of mTOR signaling [42]. However, in starvation induced autophagy, TRAF6 mediates K63-linked polyubiquitination of ULK1, which leads to stabilization of ULK1 and activation of autophagy [225]. Therefore, E3 ligases and DUBs act in a context-dependent manner. Their exact roles in cancer may vary according to their substrates, tissues types, tumor stages, or different metabolic conditions. The study of ubiquitination and deubiquitination in cancer still has a long way to go. For example, whether metabolite levels within cancer cells act as modulators of ubiquitination is ambiguous. Importantly, development of specific drugs that disrupt or enhance specific E3 ligases/DUBs-substrates interactions holds promise for more efficient and less toxic therapeutics.

What's more, we have observed that decreased ubiquitination and increased stability of the metabolic related molecules, such as PDK1, NRF2, ULK1 and phosphoglycerate kinase 1 , are associated with chemoresistance in various cancers. Thereby, modulating the activity of E3 ligases or DUBs could be exploited as a potential strategy for controlling chemoresistance in cancer treatment. Furthermore, various E3 ligases and DUBs have been already identified as potential targets for cancer therapy. Actually, many E3 ligases serve as tumor suppressors by catalyzing ubiquitination and degradation of metabolic related proteins which play oncogenic roles in cancers, indicating that drugs enhancing activities or expression of these E3 ligases should also be emphasized in further researches.

In conclusion, ubiquitination and deubiquitination are suggested to be essential regulators of metabolic reprogramming in cancer cells, demanding more studies in the future with the aim of improving cancer therapy.

\begin{abstract}
Abbreviations
LDH-A: L-lactate dehydrogenase A chain; mTORC1: Mechanistic target of rapamycin complex 1; HIF-1: Hypoxia-inducible factor 1; SREBP: Sterol regulatory element-binding protein; TCA: Tricarboxylic acid; AMPK: 5'-AMPactivated protein kinase; ROS: Reactive oxygen species; NRF2: Nuclear factor erythroid 2-related factor 2; HECT: Homology to E6AP C terminus; RBR: RINGbetween-RING; RING: Really interesting new gene; DUB: Deubiquitinating enzyme; USP: Ub-specific protease; UCH: Ub C-terminal hydrolase;

OUT: Ovarian tumor protease; MJD: Machado-Josephin domain protease; JAMM: JAB1/MPN+/MOV34; DYRK2: Dual specificity tyrosine-phosphorylationregulated kinase 2; IDH1/2: Isocitrate dehydrogenase1/2; TSC: Tuberous sclerosis complex; PDK1: 3-phosphoinositide-dependent protein kinase 1; PTEN: Phosphatase and tensin homolog; GLUT1: Glucose transporter type 1; HK1: Hexokinase 1; PDK: Pyruvate dehydrogenase kinase; AMBRA1: Activating molecule in BECN1-regulated autophagy protein 1;

PFK: Phosphofructokinase; PFKL: PFK liver type; PFKP: PFK1 platelet isoform; PFKFB3: 6-phosphofructo-2-kinase/fructose-2,6-bisphosphatase 3;

GLS1: Glutaminase 1; PKM2: Pyruvate kinase M2; PGK1: Phosphoglycerate kinase 1; PGAM5: Phosphoglycerate mutase 5; a-KGDH: a-ketoglutarate dehydrogenase; G6PD: Glucose-6-phosphate dehydrogenase; PEPC K1: Phosphoenolpyruvate carboxykinase 1; PDH: Pyruvate dehydrogenase; FBP1: Fructose-1,6-biphosphatase; AGL: Glycogen debranching enzyme; ACLY: ATP citrate lyase; ACC: Acetyl-coenzyme A carboxylase; FASN: Fatty acid synthase; HMGCR: 3-hydroxy-3-methylglutaryl-coenzyme A reductase; SQLE: Squalene epoxidase; CPT1: Carnitine O-palmitoyltransferase 1; MDR: Multidrug resistant; ASCT2: Neutral amino acid transporter B; PHGD H: D-3-phosphoglycerate dehydrogenase; SHMT1: Serine hydroxymethyltransferase 1
\end{abstract}

\section{Acknowledgements}

Not applicable.

\section{Authors' contributions}

T.S., Z.L. and Q.Y. conceived the review. T.S. and Z.L. wrote the first version of the manuscript. Q.Y. revised the manuscript. All of the authors approved the final version of the manuscript.

\section{Funding}

This research was supported by National Natural Science Foundation of China (Grant/Award Numbers: 81872125). 


\section{Availability of data and materials}

All the data obtained and/or analyzed during the current study were available from the corresponding authors on reasonable request.

\section{Ethics approval and consent to participate}

Not applicable.

\section{Consent for publication}

All authors give consent for the publication of manuscript in Molecular Cancer.

\section{Competing interests}

The authors declare that there is no potential competing interest.

\section{Author details}

'Department of Obstetrics and Gynecology, Shengjing Hospital of China Medical University, No. 36, Sanhao Street, Heping District, Shenyang 110004, China. ${ }^{2}$ Department of Urology, First Hospital of China Medical University, Shenyang, China.

\section{Received: 15 July 2020 Accepted: 23 September 2020}

Published online: 01 October 2020

\section{References}

1. DeBerardinis RJ, Chandel NS. Fundamentals of cancer metabolism. Sci Adv 2016:2:e1600200

2. Lunt SY, Vander Heiden MG. Aerobic glycolysis: meeting the metabolic requirements of cell proliferation. Annu Rev Cell Dev Biol. 2011;27:441-64.

3. Faubert B, Li KY, Cai L, Hensley CT, Kim J, Zacharias LG, Yang C, Do QN, Doucette $S$, Burguete $D$, et al. Lactate metabolism in human lung tumors. Cell. 2017:171:358-371 e359.

4. Moreau P, Attal M, Caillot D, Macro M, Karlin L, Garderet L, Facon T, Benboubker L, Escoffre-Barbe M, Stoppa AM, et al. Prospective evaluation of magnetic resonance imaging and [(18)F]Fluorodeoxyglucose positron emission tomography-computed tomography at diagnosis and before maintenance therapy in symptomatic patients with multiple myeloma included in the IFM/DFCI 2009 trial: results of the IMAJEM study. J Clin Oncol. 2017:35:2911-8

5. Xie H, Hanai J, Ren JG, Kats L, Burgess K, Bhargava P, Signoretti S, Billiard J, Duffy KJ, Grant A, et al. Targeting lactate dehydrogenase--a inhibits tumorigenesis and tumor progression in mouse models of lung cancer and impacts tumor-initiating cells. Cell Metab. 2014:19:795-809.

6. Wang YH, Israelsen WJ, Lee D, Yu WWC, Jeanson NT, Clish CB, Cantley LC, Vander Heiden MG, Scadden DT. Cell-state-specific metabolic dependency in hematopoiesis and leukemogenesis. Cell. 2014;158:1309-23.

7. Antao AM, Tyagi A, Kim KS, Ramakrishna S. Advances in deubiquitinating enzyme inhibition and applications in cancer therapeutics. Cancers (Basel). 2020;12.

8. Park HB, Kim JW, Baek KH. Regulation of Wnt signaling through ubiquitination and deubiquitination in cancers. Int J Mol Sci. 2020;21.

9. Mansour MA. Ubiquitination: friend and foe in cancer. Int J Biochem Cell Biol. 2018;101:80-93.

10. Mennerich D, Kubaichuk K, Kietzmann T. DUBs, hypoxia, and cancer. Trends Cancer. 2019;5:632-53

11. Deng L, Meng T, Chen L, Wei W, Wang P. The role of ubiquitination in tumorigenesis and targeted drug discovery. Signal Transduct Target Ther. 2020;5:11.

12. Laplante M, Sabatini DM. mTOR signaling in growth control and disease Cell. 2012;149:274-93.

13. Dibble CC, Manning BD. Signal integration by mTORC1 coordinates nutrient input with biosynthetic output. Nat Cell Biol. 2013;15:555-64

14. Dutchak PA, Estill-Terpack SJ, Plec AA, Zhao X, Yang C, Chen J, Ko B, Deberardinis RJ, Yu Y, Tu BP. Loss of a negative regulator of mTORC induces aerobic glycolysis and altered fiber composition in skeletal muscle. Cell Rep. 2018;23:1907-14.

15. Csibi A, Fendt SM, Li C, Poulogiannis G, Choo AY, Chapski DJ, Jeong SM Dempsey JM, Parkhitko A, Morrison T, et al. The mTORC1 pathway stimulates glutamine metabolism and cell proliferation by repressing SIRT4 Cell. 2013;153:840-54.
16. Mikalayeva V, Cesleviciene I, Sarapiniene I, Zvikas V, Skeberdis VA, Jakstas V, Bordel S. Fatty acid synthesis and degradation interplay to regulate the oxidative stress in cancer cells. Int J Mol Sci. 2019;20.

17. Barker RM, Holly JMP, Biernacka KM, Allen-Birt SJ, Perks CM. Mini review: opposing pathologies in cancer and alzheimer's disease: does the PI3K/Akt pathway provide clues? Front Endocrinol (Lausanne). 2020;11:403.

18. Holczer M, Hajdu B, Lorincz T, Szarka A, Banhegyi G, Kapuy O. A double negative feedback loop between mTORC1 and AMPK kinases guarantees precise autophagy induction upon cellular stress. Int J Mol Sci. 2019;20.

19. Zhao XA, Petrashen AP, Sanders JA, Peterson AL, Sedivy JM. SLC1A5 glutamine transporter is a target of MYC and mediates reduced mTORC1 signaling and increased fatty acid oxidation in long-lived Myc hypomorphic mice. Aging Cell. 2019;18.

20. Maddocks ODK, Berkers CR, Mason SM, Zheng L, Blyth K, Gottlieb E, Vousden $\mathrm{KH}$. Serine starvation induces stress and p53-dependent metabolic remodelling in cancer cells. Nature. 2013;493:542.

21. Kim D, Fiske BP, Birsoy K, Freinkman E, Kami K, Possemato RL, Chudnovsky Y, Pacold ME, Chen WW, Cantor JR, et al. SHMT2 drives glioma cell survival in ischaemia but imposes a dependence on glycine clearance. Nature. 2015; 520:363-+.

22. Sies H, Jones DP. Reactive oxygen species (ROS) as pleiotropic physiological signalling agents. Nat Rev Mol Cell Biol. 2020;21:363-83.

23. Li X, Liang M, Jiang JX, He RZ, Wang M, Guo XJ, Shen M, Qin RY. Combined inhibition of autophagy and Nrf2 signaling augments bortezomib-induced apoptosis by increasing ROS production and ER stress in pancreatic cancer cells. Int J Biol Sci. 2018;14:1291-305.

24. Khan MS, Hwang J, Lee K, Choi Y, Seo Y, Jeon H, Hong JW, Choi J. Antitumor drug-loaded oxygen nanobubbles for the degradation of HIF-1 alpha and the upregulation of reactive oxygen species in tumor cells. Cancers. 2019;11.

25. Follo C, Vidoni C, Morani F, Ferraresi A, Seca C, Isidoro C. Amino acid response by halofuginone in cancer cells triggers autophagy through proteasome degradation of mTOR. Cell Commun Signal. 2019;17.

26. Yu L, Chen Y, Tooze SA. Autophagy pathway: cellular and molecular mechanisms. Autophagy. 2018;14:207-15.

27. Lock R, Roy S, Kenific CM, Su JS, Salas E, Ronen SM, Debnath J. Autophagy facilitates glycolysis during Ras-mediated oncogenic transformation. Mol Biol Cell. 2011;22:165-78.

28. Zhang C, Lin M, Wu R, Wang X, Yang B, Levine AJ, Hu W, Feng Z. Parkin, a p53 target gene, mediates the role of p53 in glucose metabolism and the Warburg effect. Proc Natl Acad Sci U S A. 2011;108:16259-64.

29. Martinez-Outschoorn UE, Pavlides S, Howell A, Pestell RG, Tanowitz HB, Sotgia F, Lisanti MP. Stromal-epithelial metabolic coupling in cancer: integrating autophagy and metabolism in the tumor microenvironment. Int J Biochem Cell Biol. 2011:43:1045-51.

30. Hershko A, Ciechanover A. The ubiquitin system. Annu Rev Biochem. 1998; $67 \cdot 425-79$

31. Sewduth RN, Baietti MF, Sablina AA. Cracking the monoubiquitin code of genetic diseases. Int J Mol Sci. 2020;21.

32. Baur R, Rape M. Getting close: insight into the structure and function of K11/K48-branched ubiquitin chains. Structure. 2020;28:1-3.

33. Yao T, Ndoja A. Regulation of gene expression by the ubiquitin-proteasome system. Semin Cell Dev Biol. 2012;23:523-9.

34. Flick K, Raasi S, Zhang H, Yen JL, Kaiser P. A ubiquitin-interacting motif protects polyubiquitinated Met4 from degradation by the 265 proteasome. Nat Cell Biol. 2006;8:509-15.

35. Le Cam L, Linares LK, Paul C, Julien E, Lacroix M, Hatchi E, Triboulet R, Bossis G, Shmueli A, Rodriguez MS, et al. E4F1 is an atypical ubiquitin ligase that modulates p53 effector functions independently of degradation. Cell. 2006: 127:775-88.

36. Glickman $\mathrm{MH}$, Ciechanover $\mathrm{A}$. The ubiquitin-proteasome proteolytic pathway: destruction for the sake of construction. Physiol Rev. 2002;82:373428.

37. Tang R, Langdon WY, Zhang J. Regulation of immune responses by E3 ubiquitin ligase Cbl-b. Cell Immunol. 2019;340

38. Popovic D, Vucic D, Dikic I. Ubiquitination in disease pathogenesis and treatment. Nat Med. 2014;20:1242-53.

39. Rogers-Broadway KR, Kumar J, Sisu C, Wander G, Mazey E, Jeyaneethi J, Pados G, Tsolakidis D, Klonos E, Grunt T, et al. Differential expression of mTOR components in endometriosis and ovarian cancer: effects of 
rapalogues and dual kinase inhibitors on mTORC1 and mTORC2 stoichiometry. Int J Mol Med. 2019;43:47-56.

40. Wang $P$, Zhang $Q$, Tan $L, X u$ YN, Xie XB, Zhao $Y$. The regulatory effects of mTOR complexes in the differentiation and function of CD4(+) T cell subsets. J Immunol Res. 2020;2020.

41. Rogala KB, Gu X, Kedir JF, Abu-Remaileh M, Bianchi LF, Bottino AMS, Dueholm R, Niehaus A, Overwijn D, Fils ACP, et al. Structural basis for the docking of mTORC1 on the lysosomal surface. Science. 2019;366:468-+.

42. Linares JF, Duran A, Yajima T, Pasparakis M, Moscat J, Diaz-Meco MT. K63 polyubiquitination and activation of mTOR by the p62-TRAF6 complex in nutrient-activated cells. Mol Cell. 2013:51:283-96.

43. Mao JH, Kim IJ, Wu D, Climent J, Kang HC, DelRosario R, Balmain A. FBXW7 targets mTOR for degradation and cooperates with PTEN in tumor suppression. Science. 2008;321:1499-502.

44. Wang FF, Zhang XJ, Yan YR, Zhu XH, Yu J, Ding Y, Hu JL, Zhou WJ, Zeng ZC, Liao WT, et al. FBX8 is a metastasis suppressor downstream of miR-223 and targeting mTOR for degradation in colorectal carcinoma. Cancer Lett. 2017; 388:85-95.

45. Mimoto R, Nihira NT, Hirooka S, Takeyama H, Yoshida K. Diminished DYRK2 sensitizes hormone receptor-positive breast cancer to everolimus by the escape from degrading mTOR. Cancer Lett. 2017;384:27-38.

46. Kim SY, Kim HJ, Kim HJ, Kim CH. Non-thermal plasma induces antileukemic effect through mTOR ubiquitination. Cells. 2020;9.

47. Park D, Lee MN, Jeong H, Koh A, Yang YR, Suh PG, Ryu SH. Parkin ubiquitinates $\mathrm{mTOR}$ to regulate $\mathrm{mTORC1}$ activity under mitochondrial stress. Cell Signal. 2014;26:2122-30.

48. Agrawal $P$, Chen $Y T$, Schilling B, Gibson BW, Hughes RE. Ubiquitin-specific peptidase 9, X-linked (USP9X) modulates activity of mammalian target of rapamycin (mTOR). J Biol Chem. 2012;287:21164-75.

49. Hussain S, Feldman AL, Das C, Ziesmer SC, Ansell SM, Galardy PJ. Ubiquitin hydrolase UCH-L1 destabilizes mTOR complex 1 by antagonizing DDB1CUL4-mediated ubiquitination of raptor. Mol Cell Biol. 2013;33:1188-97.

50. Wang B, Jie ZL, Joo DH, Ordureau A, Liu P, Gan WJ, Guo JP, Zhang JF, North BJ, Dai XP, et al. TRAF2 and OTUD7B govern a ubiquitin-dependent switch that regulates mTORC2 signalling. Nature. 2017;545:365-+

51. Carbonneau M, Gagne LM, Lalonde ME, Germain MA, Motorina A, Guiot MC, Secco B, Vincent EE, Tumber A, Hulea L, et al. The oncometabolite 2hydroxyglutarate activates the mTOR signalling pathway. Nat Commun. 2016;7.

52. Chen L, Liu TY, Tu YH, Rong DY, Cao Y. Cul1 promotes melanoma cell proliferation by promoting DEPTOR degradation and enhancing capdependent translation. Oncol Rep. 2016;35:1049-56.

53. Tan MJ, Xu J, Siddiqui J, Feng FL, Sun Y. Depletion of SAG/RBX2 E3 ubiquitin ligase suppresses prostate tumorigenesis via inactivation of the PI3K/AKT/mTOR axis. Mol Cancer. 2016;15.

54. Zhao LL, Wang XB, Yu Y, Deng L, Chen L, Peng XP, Jiao CC, Gao GL, Tan X, Pan WJ, et al. OTUB1 protein suppresses mTOR complex 1 (mTORC1) activity by deubiquitinating the mTORC1 inhibitor DEPTOR. J Biol Chem. 2018;293:4883-92

55. Antonioli M, Albiero F, Nazio F, Vescovo T, Perdomo AB, Corazzari M, Marsella C, Piselli P, Gretzmeier C, Dengjel J, et al. AMBRA1 interplay with cullin E3 ubiquitin ligases regulates autophagy dynamics. Dev Cell. 2014;31: 734-46.

56. Luo ZG, Pan YF, Jeong LS, Liu J, Jia LJ. Inactivation of the cullin (CUL)-RING E3 ligase by the NEDD8-activating enzyme inhibitor MLN4924 triggers protective autophagy in cancer cells. Autophagy. 2012;8:1677-9.

57. Feng JB, Zhang Y, Ren X, Li D, Fu HJ, Liu CH, Zhou W, Liu Q, Liu Q, Wu MH. Leucine-rich repeat containing 4 act as an autophagy inhibitor that restores sensitivity of glioblastoma to temozolomide. Oncogene. 2020;39:4551-66.

58. Deng L, Jiang C, Chen L, Jin J, Wei J, Zhao L, Chen M, Pan W, Xu Y, Chu H, et al. The ubiquitination of rag A GTPase by RNF152 negatively regulates mTORC1 activation. Mol Cell. 2015;58:804-18.

59. Jin GX, Lee SW, Zhang X, Cai Z, Gao Y, Chou PC, Rezaeian AH, Han F, Wang CY, Yao JC, et al. Skp2-mediated RagA ubiquitination elicits a negative feedback to prevent amino-acid-dependent mTORC1 hyperactivation by recruiting GATOR1. Mol Cell. 2015;58:989-1000.

60. Chen J, Ou YH, Yang YY, Li W, Xu Y, Xie YT, Liu Y. KLHL22 activates aminoacid-dependent mTORC1 signalling to promote tumorigenesis and ageing. Nature. 2018;557:585.
61. Deng $L$, Chen $L$, Zhao $L L, X u Y$, Peng $X P$, Wang $X B$, Ding $L$, Jin $J$, Teng $H Q$, Wang $Y M$, et al. Ubiquitination of Rheb governs growth factor-induced mTORC1 activation. Cell Res. 2019;29:136-50.

62. Guo P, Ma X, Zhao W, Huai W, Li T, Qiu Y, Zhang Y, Han L. TRIM31 is upregulated in hepatocellular carcinoma and promotes disease progression by inducing ubiquitination of TSC1-TSC2 complex. Oncogene. 2018;37:47888.

63. Hu J, Zacharek S, He YJ, Lee H, Shumway S, Duronio RJ, Xiong Y. WD40 protein FBW5 promotes ubiquitination of tumor suppressor TSC2 by DDB1CUL4-ROC1 ligase. Genes Dev. 2008;22:866-71.

64. Han S, Witt RM, Santos TM, Polizzano C, Sabatini BL, Ramesh V. Pam (protein associated with Myc) functions as an E3 ubiquitin ligase and regulates TSC/ mTOR signaling. Cell Signal. 2008;20:1084-91.

65. Zheng L, Ding HR, Lu ZM, Li Y, Pan YQ, Ning T, Ke Y. E3 ubiquitin ligase E6AP-mediated TSC2 turnover in the presence and absence of HPV16 E6. Genes Cells. 2008;13:285-94.

66. Chong-Kopera H, Inoki K, Li Y, Zhu TQ, Garcia-Gonzalo FR, Rosa JL, Guan KL. TSC1 stabilizes TSC2 by inhibiting the interaction between TSC2 and the HERC1 ubiquitin ligase. J Biol Chem. 2006;281:8313-6.

67. Mohan N, Shen Y, Dokmanovic M, Endo Y, Hirsch DS, Wu WJ. VPS34 regulates TSC1/TSC2 heterodimer to mediate RheB and mTORC1/S6K1 activation and cellular transformation. Oncotarget. 2016;7:52239-54.

68. Madigan JP, Hou F, Ye LL, Hu JC, Dong AP, Tempel W, Yohe ME, Randazzo PA, Jenkins LMM, Gottesman MM, Tong YF. The tuberous sclerosis complex subunit TBC1D7 is stabilized by Akt phosphorylation-mediated 14-3-3 binding. J Biol Chem. 2018;293:16142-59.

69. Rodriguez-Escudero I, Roelants FM, Thorner J, Nombela C, Molina M, Cid VJ. Reconstitution of the mammalian PI3K/PTEN/Akt pathway in yeast. Biochem J. 2005;390:613-23.

70. Wang ZX, Dang TT, Liu TT, Chen S, Li L, Huang S, Fang M. NEDD4L protein catalyzes ubiquitination of PIK3CA protein and regulates PI3K-AKT signaling. J Biol Chem. 2016;291:17467-77.

71. Hamidi A, Song J, Thakur N, Itoh S, Marcusson A, Bergh A, Heldin CH, Landstrom M. TGF-beta promotes PI3K-AKT signaling and prostate cancer cell migration through the TRAF6-mediated ubiquitylation of p85 alpha. Sci Signal. 2017;10.

72. Jiang J, Xu YT, Ren HJ, Wudu M, Wang QZ, Song X, Su HB, Jiang XZ, Jiang LH, Qiu XS. MKRN2 inhibits migration and invasion of non-small-cell lung cancer by negatively regulating the PI3K/Akt pathway. J Exp Clin Cancer Res. 2018:37.

73. Ko HR, Kim CK, Lee SB, Song J, Lee KH, Kim KK, Park KW, Cho SW, Ahn JY. P42 Ebp1 regulates the proteasomal degradation of the p85 regulatory subunit of PI3K by recruiting a chaperone-E3 ligase complex HSP70/CHIP. Cell Death Dis. 2014;5.

74. Kuchay S, Duan SS, Schenkein E, Peschiaroli A, Saraf A, Florens L, Washburn MP, Pagano M. FBXL2-and PTPL1-mediated degradation of p110-free p85 beta regulatory subunit controls the PI(3)K signalling cascade. Nat Cell Biol. 2013;15:472-+.

75. Wu YH, Chang TH, Huang YF, Chen CC, Chou CY. COL11A1 confers chemoresistance on ovarian cancer cells through the activation of Akt/c/ EBP beta pathway and PDK1 stabilization. Oncotarget. 2015;6:23748-63.

76. Uras IZ, List T, Nijman SMB. Ubiquitin-specific protease 4 inhibits monoubiquitination of the master growth factor signaling kinase PDK1. PLoS One. 2012;7.

77. Chan CH, Li CF, Yang WL, Gao Y, Lee SW, Feng ZZ, Huang HY, Tsai KKC, Flores LG, Shao YP, et al. The Skp2-SCF E3 ligase regulates Akt ubiquitination, glycolysis, herceptin sensitivity, and tumorigenesis (vol 149, pg 1098, 2012). Cell. 2012;151:913-4.

78. Yang WL, Wang J, Chan CH, Lee SW, Campos AD, Lamothe B, Hur L, Grabiner BC, Lin X, Darnay BG, Lin HK. The E3 ligase TRAF6 regulates Akt ubiquitination and activation. Science. 2009:325:1134-8.

79. Fan CD, Lum MA, Xu C, Black JD, Wang XJ. Ubiquitin-dependent regulation of phospho-AKT dynamics by the ubiquitin E3 ligase, NEDD4-1, in the insulin-like growth factor-1 response. J Biol Chem. 2013;288:1674-84.

80. Li W, Peng C, Lee MH, Lim D, Zhu F, Fu Y, Yang G, Sheng YQ, Xiao LB, Dong $X$, et al. TRAF4 is a critical molecule for Akt activation in lung cancer. Cancer Res. 2013;73:6938-50.

81. Zhang JD, Yang ZF, Ou JY, Xia XJ, Zhi F, Cui J. The F-box protein FBXL18 promotes glioma progression by promoting K63-linked ubiquitination of Akt. FEBS Lett. 2017:591:145-54. 
82. Liang CX, Liang GY, Zheng XQ, Huang YX, Huang SH, Yin D. RSP5 positively regulates the osteogenic differentiation of mesenchymal stem cells by activating the K63-linked ubiquitination of Akt. Stem Cells Int. 2020;2020.

83. Wang GH, Long J, Gao Y, Zhang WN, Han F, Xu C, Sun L, Yang SC, Lan JQ, Hou ZL, et al. SETDB1-mediated methylation of Akt promotes its K63-linked ubiquitination and activation leading to tumorigenesis. Nat Cell Biol. 2019; 21:214.

84. Li HJ, Lan JQ, Wang GH, Guo KX, Han CS, Li XL, Hu JB, Cao ZX, Luo XL. KDM4B facilitates colorectal cancer growth and glucose metabolism by stimulating TRAF6-mediated AKT activation. J Exp Clin Cancer Res. 2020;39.

85. Lim JH, Jono H, Komatsu K, Woo CH, Lee J, Miyata M, Matsuno T, Xu XB, Huang YX, Zhang WH, et al. CYLD negatively regulates transforming growth factor-beta-signalling via deubiquitinating Akt. Nat Commun. 2012;3.

86. Yin $\mathrm{FL}$, He HG, Zhang B, Zheng $\mathrm{JH}$, Wang $\mathrm{M}$, Zhang $\mathrm{M}$, Cui HX. Effect of deubiquitinase ovarian tumor domain-containing protein 5 (OTUD5) on radiosensitivity of cervical cancer by regulating the ubiquitination of Akt and its mechanism. Med Sci Monit. 2019;25:3469-75.

87. Goldbraikh D, Neufeld D, Eid-Mutlak Y, Lasry I, Gilda JE, Parnis A, Cohen S. USP1 deubiquitinates Akt to inhibit PI3K-Akt-FoxO signaling in muscle during prolonged starvation. EMBO Rep. 2020;21.

88. Qiu CJ, Liu KR, Zhang S, Gao SM, Chen WR, Li DT, Huang YX. Bisdemethoxycurcumin inhibits hepatocellular carcinoma proliferation through Akt inactivation via CYLD-mediated deubiquitination. Drug Des Devel Ther. 2020;14:993-1001.

89. Xiang T, Ohashi A, Huang YP, Pandita TK, Ludwig T, Powell SN, Yang Q. Negative regulation of AKT activation by BRCA1. Cancer Res. 2008;68:100404.

90. Suizu F, Hiramuki Y, Okumura F, Matsuda M, Okumura AJ, Hirata N, Narita M, Kohno T, Yokota J, Bohgaki M, et al. The E3 ligase TTC3 facilitates ubiquitination and degradation of phosphorylated Akt. Dev Cell. 2009;17: 800-10.

91. Joo HM, Kim JY, Jeong JB, Seong KM, Nam SY, Yang KH, Kim CS, Kim HS, Jeong $M, A n S$, Jin YW. Ret finger protein 2 enhances ionizing radiationinduced apoptosis via degradation of AKT and MDM2. Eur J Cell Biol. 2011; 90:420-31.

92. Bae SH, Kim SY, Jung JH, Yoon YM, Cha HJ, Lee HJ, Kim K, Kim J, An IS, Kim J, et al. Akt is negatively regulated by the MULAN E3 ligase. Cell Res. 2012; 22:873-85.

93. Su CH, Wang CY, Lan KH, Li CP, Chao Y, Lin HC, Lee SD, Lee WP. Akt phosphorylation at Thr308 and Ser473 is required for CHIP-mediated ubiquitination of the kinase. Cell Signal. 2011;23:1824-30.

94. Wakatsuki S, Saitoh F, Araki T. ZNRF1 promotes Wallerian degeneration by degrading AKT to induce GSK3B-dependent CRMP2 phosphorylation. Nat Cell Biol. 2011;13:1415-U1259.

95. Athamneh K, El Hasasna H, Al Samri H, Attoub S, Arafat K, Benhalilou N, Al Rashedi A, Al Dhaheri Y, AbuQamar S, Eid A, Iratni R. Rhus coriaria increases protein ubiquitination, proteasomal degradation and triggers non-canonical Beclin-1-independent autophagy and apoptotic cell death in colon cancer cells. Sci Rep. 2017;7.

96. Su X, Shen Z, Yang Q, Sui F, Pu J, Ma JJ, Ma SR, Yao DM, Ji MJ, Hou P. Vitamin C kills thyroid cancer cells through ROS-dependent inhibition of MAPKJERK and PI3K/AKT pathways via distinct mechanisms. Theranostics. 2019:9:4461-73.

97. Kim HJ, Kim SY, Kim DH, Park JS, Jeong SH, Choi YW, Kim CH. Crosstalk between HSPA5 arginylation and sequential ubiquitination leads to AKT degradation through autophagy flux. Autophagy. 2020.

98. Trotman LC, Wang XJ, Alimonti A, Chen ZB, Teruya-Feldstein J, Yang HJ, Pavletich NP, Carver BS, Cordon-Cardo C, Erdjument-Bromage H, et al. Ubiquitination regulates PTEN nuclear import and tumor suppression. Cell. 2007;128:141-56

99. Shen X, Zhong JX, Yu P, Zhao QY, Huang T. YY1-regulated LINC00152 promotes triple negative breast cancer progression by affecting on stability of PTEN protein. Biochem Biophys Res Commun. 2019;509:448-54.

100. Maddika S, Kavela S, Rani N, Palicharla VR, Pokorny JL, Sarkaria JN, Chen JJ. WWP2 is an E3 ubiquitin ligase for PTEN. Nat Cell Biol. 2011;13:728-U224.

101. Yang H, Wang XX, Zhou CY, Xiao X, Tian C, Li HH, Yin CL, Wang HX. Tripartite motif 10 regulates cardiac hypertrophy by targeting the PTEN/AKT pathway. J Cell Mol Med. 2020;24:6233-41.

102. Yuan $P$, Zheng AD, Tang Q. Tripartite motif protein 25 is associated with epirubicin resistance in hepatocellular carcinoma cells via regulating PTEN/ AKT pathway. Cell Biol Int. 2020;44:1503-13.
103. He R, Liu HX. TRIM59 knockdown blocks cisplatin resistance in A549/DDP cells through regulating PTEN/AKT/HK2. Gene. 2020;747.

104. Ma L, Yao NH, Chen P, Zhuang ZX. TRIM27 promotes the development of esophagus cancer via regulating PTEN/AKT signaling pathway. Cancer Cell Int. 2019;19.

105. Shen WD, Jin ZH, Tong XP, Wang HY, Zhuang LL, Lu XF, Wu SB. TRIM14 promotes cell proliferation and inhibits apoptosis by suppressing PTEN in colorectal cancer. Cancer Manag Res. 2019;11:5725-35.

106. Van Themsche C, Leblanc V, Parent S, Asselin E. X-linked inhibitor of apoptosis protein (XIAP) regulates PTEN ubiquitination, content, and compartmentalization. J Biol Chem. 2009;284:20462-6.

107. Lee MS, Jeong MH, Lee HW, Han HJ, Ko A, Hewitt SM, Kim JH, Chun KH, Chung JY, Lee C, et al. PI3K/AKT activation induces PTEN ubiquitination and destabilization accelerating tumourigenesis. Nat Commun. 2015;6.

108. Lee YR, Chen M, Lee JD, Zhang J, Lin SY, Fu TM, Chen H, Ishikawa T, Chiang SY, Katon J, et al. Reactivation of PTEN tumor suppressor for cancer treatment through inhibition of a MYC-WWP1 inhibitory pathway. Science. 2019;364.

109. Lee JT, Shan J, Zhong JY, Li MY, Zhou B, Zhou A, Parsons R, Gu W. RFPmediated ubiquitination of PTEN modulates its effect on AKT activation. Cell Res. 2013;23:552-64.

110. Sun J, Li TX, Zhao YY, Huang LR, Sun H, Wu H, Jiang XF. USP10 inhibits lung cancer cell growth and invasion by upregulating PTEN. Mol Cell Biochem. 2018:441:1-7.

111. Zhang JS, Zhang PJ, Wei YK, Piao HL, Wang WQ, Maddika S, Wang M, Chen $D H$, Sun $Y$, Hung MC, et al. Deubiquitylation and stabilization of PTEN by USP13. Nat Cell Biol. 2013;15:1486.

112. Yuan L, Lv YR, Li HC, Gao HD, Song SS, Zhang Y, Xing GC, Kong XZ, Wang L, Li Y, et al. Deubiquitylase OTUD3 regulates PTEN stability and suppresses tumorigenesis (vol 17, pg 1169, 2015). Nat Cell Biol. 2015;17.

113. Shen WM, Yin JN, Xu RJ, Xu DF, Zheng SY. Ubiquitin specific peptidase 49 inhibits non-small cell lung cancer cell growth by suppressing PI3K/AKT signaling. Kaohsiung J Med Sci. 2019;35:401-7.

114. Zhang H, Wei PT, Lv WW, Han XT, Yang JH, Qin SF. Long noncoding RNA Inc-DILC stabilizes PTEN and suppresses clear cell renal cell carcinoma progression. Cell Biosci. 2019;9.

115. Morotti A, Panuzzo C, Crivellaro S, Pergolizzi B, Familiari U, Berger AH, Saglio G, Pandolfi PP. BCR-ABL disrupts PTEN nuclear-cytoplasmic shuttling through phosphorylation-dependent activation of HAUSP. Leukemia. 2014; 28:1326-33.

116. Wu Y, Zhou H, Wu K, Lee S, Li RJ, Liu X. PTEN phosphorylation and nuclear export mediate free fatty acid-induced oxidative stress. Antioxid Redox Signal. 2014;20:1382-95.

117. Sacco JJ, Yau TY, Darling S, Patel V, Liu H, Urbe S, Clague MJ, Coulson JM. The deubiquitylase Ataxin-3 restricts PTEN transcription in lung cancer cells. Oncogene. 2014;33:4265-72.

118. Pineda CT, Ramanathan S, Tacer KF, Weon JL, Potts MB, Ou YH, White MA, Potts PR. Degradation of AMPK by a cancer-specific ubiquitin ligase. Cell. 2015;160:715-28.

119. Kwon E, Li X, Deng Y, Chang HW, Kim DY. AMPK is down-regulated by the CRL4A-CRBN axis through the polyubiquitination of AMPKalpha isoforms. FASEB J. 2019;33:6539-50.

120. Vila IK, Song SJ, Song MS. A new duet in cancer biology: AMPK the typical and UBE2O the atypical. Mol Cell Oncol. 2017:4:e1304846.

121. Yang SJ, Jeon SJ, Nguyen TV, Deshaies RJ, Park CS, Lee KM. Ubiquitindependent proteasomal degradation of AMPK gamma subunit by cereblon inhibits AMPK activity. Biochim Biophys Acta Mol Cell Res. 2020;1867.

122. Liu HZ, Ding J, Kohnlein K, Urban N, Ori A, Villavicencio-Lorini P, Walentek $P$, Klotz LO, Hollemann T, Pfirrmann T. The GID ubiquitin ligase complex is a regulator of AMPK activity and organismal lifespan. Autophagy. 2019.

123. Xu K, Park D, Magis AT, Zhang J, Zhou W, Sica GL, Ramalingam SS, Curran WJ, Deng XM. Small molecule KRAS agonist for mutant KRAS cancer therapy. Mol Cancer. 2019;18.

124. Sasaki AT, Carracedo A, Locasale JW, Anastasiou D, Takeuchi K, Kahoud ER, Haviv S, Asara JM, Pandolfi PP, Cantley LC. Ubiquitination of K-Ras enhances activation and facilitates binding to select downstream effectors. Sci Signal. 2011;4.

125. Abe T, Umeki I, Kanno S, Inoue S, Niihori T, Aoki Y. LZTR1 facilitates polyubiquitination and degradation of RAS-GTPases. Cell Death Differ. 2020; 27:1023-35. 
126. Zeng TL, Wang Q, Fu JY, Lin Q, Bi J, Ding WC, Qiao YK, Zhang S, Zhao WX, Lin HY, et al. Impeded Nedd4-1-mediated Ras degradation underlies Rasdriven tumorigenesis. Cell Rep. 2014;7:871-82.

127. Dang CV. The interplay between MYC and HIF in the Warburg effect. Ernst Schering Found Symp Proc. 2007:35-53.

128. Buckley DL, Van Molle I, Gareiss PC, Tae HS, Michel J, Noblin DJ, Jorgensen WL, Ciulli A, Crews CM. Targeting the von Hippel-Lindau E3 ubiquitin ligase using small molecules to disrupt the VHL/HIF-1alpha interaction. J Am Chem Soc. 2012;134:4465-8.

129. Guo Y, Meng X, Ma J, Zheng Y, Wang Q, Wang Y, Shang H. Human papillomavirus 16 E6 contributes HIF-1alpha induced Warburg effect by attenuating the VHL-HIF-1alpha interaction. Int J Mol Sci. 2014;15:7974-86.

130. Liu J, Zhang C, Zhao YH, Yue XT, Wu H, Huang S, Chen J, Tomsky K, Xie HY, Khella CA, et al. Parkin targets HIF-1 alpha for ubiquitination and degradation to inhibit breast tumor progression. Nat Commun. 2017;8

131. Zhang L, Cao J, Dong L, Lin H. TiPARP forms nuclear condensates to degrade HIF-1alpha and suppress tumorigenesis. Proc Natl Acad Sci U S A. 2020;117:13447-56.

132. Thirusangu P, Vigneshwaran V, Prashanth T, Vijay Avin BR, Malojirao VH, Rakesh H, Khanum SA, Mahmood R, Prabhakar BT. BP-1T, an antiangiogenic benzophenone-thiazole pharmacophore, counteracts HIF-1 signalling through p53/MDM2-mediated HIF-1alpha proteasomal degradation. Angiogenesis. 2017;20:55-71.

133. Joshi S, Singh AR, Durden DL. MDM2 regulates hypoxic hypoxia-inducible factor 1alpha stability in an E3 ligase, proteasome, and PTENphosphatidylinositol 3-kinase-AKT-dependent manner. J Biol Chem. 2014; 289:22785-97.

134. Chowdhury AR, Long A, Fuchs SY, Rustgi A, Avadhani NG. Mitochondrial stress-induced p53 attenuates HIF-1alpha activity by physical association and enhanced ubiquitination. Oncogene. 2017;36:397-409.

135. Amelio I, Inoue S, Markert EK, Levine AJ, Knight RA, Mak TW, Melino G. TAp73 opposes tumor angiogenesis by promoting hypoxia-inducible factor 1alpha degradation. Proc Natl Acad Sci U S A. 2015;112:226-31.

136. Flugel D, Gorlach A, Kietzmann T. GSK-3beta regulates cell growth, migration, and angiogenesis via Fbw7 and USP28-dependent degradation of HIF-1alpha. Blood. 2012;119:1292-301.

137. Lee SH, Jee JG, Bae JS, Liu KH, Lee YM. A group of novel HIF-1alpha inhibitors, glyceollins, blocks HIF-1alpha synthesis and decreases its stability via inhibition of the PI3K/AKT/mTOR pathway and Hsp90 binding. J Cell Physiol. 2015;230:853-62

138. Lee YM, Kim GH, Park EJ, Oh TI, Lee S, Kan SY, Kang H, Kim BM, Kim JH, Lim $J$. Thymoquinone selectively kills hypoxic renal cancer cells by suppressing HIF-1alpha-mediated glycolysis. Int J Mol Sci. 2019;20.

139. Ju UI, Park JW, Park HS, Kim SJ, Chun YS. FBXO11 represses cellular response to hypoxia by destabilizing hypoxia-inducible factor-1alpha mRNA. Biochem Biophys Res Commun. 2015;464:1008-15.

140. Chen Z, Lin TC, Bi X, Lu G, Dawson BC, Miranda R, Medeiros LJ, McNiece I, McCarty N. TRIM44 promotes quiescent multiple myeloma cell occupancy and survival in the osteoblastic niche via HIF-1alpha stabilization. Leukemia. 2019;33:469-86.

141. Wu HT, Kuo YC, Hung JJ, Huang CH, Chen WY, Chou TY, Chen Y, Chen YJ, Chen YJ, Cheng WC, et al. K63-polyubiquitinated HAUSP deubiquitinates HIF-1alpha and dictates H3K56 acetylation promoting hypoxia-induced tumour progression. Nat Commun. 2016;7:13644.

142. Park JJ, Yun JH, Baek KH. Polyclonal and monoclonal antibodies specific for ubiquitin-specific protease 20. Monoclon Antib Immunodiagn Immunother. 2013;32:193-9

143. Li Z, Wang D, Messing EM, Wu G. VHL protein-interacting deubiquitinating enzyme 2 deubiquitinates and stabilizes HIF-1alpha. EMBO Rep. 2005;6:3738.

144. Bremm A, Moniz S, Mader J, Rocha S, Komander D. Cezanne (OTUD7B) regulates HIF-1alpha homeostasis in a proteasome-independent manner. EMBO Rep. 2014;15:1268-77.

145. Troilo A, Alexander I, Muehl S, Jaramillo D, Knobeloch KP, Krek W. HIF1alpha deubiquitination by USP8 is essential for ciliogenesis in normoxia. EMBO Rep. 2014;15:77-85.

146. Sun $H$, Li XB, Meng Y, Fan L, Li M, Fang J. TRAF6 upregulates expression of HIF-1alpha and promotes tumor angiogenesis. Cancer Res. 2013;73:4950-9.

147. Park CV, Ivanova IG, Kenneth NS. XIAP upregulates expression of HIF target genes by targeting HIF1alpha for Lys63-linked polyubiquitination. Nucleic Acids Res. 2017;45:9336-47.
148. Shim H, Dolde C, Lewis BC, Wu CS, Dang G, Jungmann RA, Dalla-Favera R, Dang CV. C-Myc transactivation of LDH-A: implications for tumor metabolism and growth. Proc Natl Acad Sci U S A. 1997;94:6658-63.

149. Lee $S$, Kim W, Ko C, Ryu WS. Hepatitis B virus X protein enhances Myc stability by inhibiting SCF(Skp2) ubiquitin E3 ligase-mediated Myc ubiquitination and contributes to oncogenesis. Oncogene. 2016;35:1857-67.

150. The MULE/HUWE1 E3 ubiquitin ligase is a tumor suppressor. Cancer Discov. 2013;3:OF32.

151. Koch HB, Zhang R, Verdoodt B, Bailey A, Zhang CD, Yates JR 3rd, Menssen A, Hermeking H. Large-scale identification of C-MYC-associated proteins using a combined TAP/MudPIT approach. Cell Cycle. 2007;6:205-17.

152. Choi SH, Wright JB, Gerber SA, Cole MD. Myc protein is stabilized by suppression of a novel E3 ligase complex in cancer cells. Genes Dev. 2010; 24:1236-41.

153. Hakem A, Bohgaki M, Lemmers B, Tai E, Salmena L, Matysiak-Zablocki E, Jung YS, Karaskova J, Kaustov L, Duan SL, et al. Role of Pirh2 in mediating the regulation of p53 and c-Myc. PLoS Genet. 2011;7.

154. Paul I, Ahmed SF, Bhowmik A, Deb S, Ghosh MK. The ubiquitin ligase CHIP regulates c-Myc stability and transcriptional activity. Oncogene. 2013;32: 1284-95.

155. Fang XG, Zhou WC, Wu QL, Huang Z, Shi Y, Yang KL, Chen C, Xie Q, Mack SC, Wang XX, et al. Deubiquitinase USP13 maintains glioblastoma stem cells by antagonizing FBXL14-mediated Myc ubiquitination. J Exp Med. 2017;214: 245-67.

156. Luo LY, Tang HL, Ling L, Li N, Jia XT, Zhang ZJ, Wang XR, Shi LJ, Yin J, Qiu N, et al. LINC01638 IncRNA activates MTDH-Twist1 signaling by preventing SPOP-mediated c-Myc degradation in triple-negative breast cancer. Oncogene. 2018;37:6166-79.

157. Nicklas S, Hillje AL, Okawa S, Rudolph IM, Collmann FM, van Wuellen T, del Sol A, Schwamborn JC. A complex of the ubiquitin ligase TRIM32 and the deubiquitinase USP7 balances the level of c-Myc ubiquitination and thereby determines neural stem cell fate specification. Cell Death Differ. 2019;26: $728-40$

158. Chen J, Li WJ, Cui K, Ji KY, XU SX, Xu Y. Artemisitene suppresses tumorigenesis by inducing DNA damage through deregulating c-Myctopoisomerase pathway. Oncogene. 2018:37:5079-87.

159. Wang SQ, Wang N, Zheng YF, Yang BW, Liu PX, Zhang FX, Li M, Song JX, Chang X, Wang ZY. Caveolin-1 inhibits breast cancer stem cells via c-Mycmediated metabolic reprogramming. Cell Death Dis. 2020;11.

160. Gonzalez-Pecchi V, Kwan AK, Doyle S, Ivanov AA, Du Y, Fu H. NSD3S stabilizes MYC through hindering its interaction with FBXW7. J Mol Cell Biol. 2020;12:438-47.

161. Sriratanasak N, Petsri K, Laobuthee A, Wattanathana W, Vinayanuwattikun C, Luanpitpong S, Chanvorachote P. Novel c-Myctargeting compound N, N-Bis (5-Ethyl-2-Hydroxybenzyl) methylamine for mediated c-Myc ubiquitin-proteasomal degradation in lung cancer cells. Mol Pharmacol. 2020:98:130-42.

162. Fiore D, Piscopo C, Proto MC, Vasaturo M, Dal Piaz F, Fusco BM, Pagano C, Laezza C, Bifulco M, Gazzerro P. N6-Isopentenyladenosine inhibits colorectal cancer and improves sensitivity to 5-fluorouracil targeting FBXW7 tumor suppressor. Cancers. 2019;11.

163. Hu Y, Yu K, Wang G, Zhang D, Shi C, Ding Y, Hong D, Zhang D, He H, Sun L, et al. Lanatoside $C$ inhibits cell proliferation and induces apoptosis through attenuating Wnt/ $\beta$-catenin/c-Myc signaling pathway in human gastric cancer cell. Biochem Pharmacol. 2018;150:280-92.

164. Morel M, Shah KN, Long WW. The F-box protein FBXL16 up-regulates the stability of C-MYC oncoprotein by antagonizing the activity of the F-box protein FBW7. J Biol Chem. 2020;295:7970-80.

165. Mao CG, Zhou XC, Jiang YD, Wan LJ, Tao ZZ, Guo J. The Evi5 oncogene promotes laryngeal cancer cells proliferation by stabilizing c-Myc protein. Cancer Cell Int. 2020;20.

166. Ma S, Lu CC, Yang LY, Wang JJ, Wang BS, Cai HQ, Hao JJ, Xu X, Cai Y, Zhang $Y$, Wang MR. ANXA2 promotes esophageal cancer progression by activating MYC-HIF1A-VEGF axis. J Exp Clin Cancer Res. 2018:37.

167. He J, Li FZ, Zhou Y, Hou XY, Liu SS, Li XC, Zhang YW, Jing XQ, Yang LP. LncRNA XLOC_006390 promotes pancreatic carcinogenesis and glutamate metabolism by stabilizing c-Myc. Cancer Lett. 2020;469:419-28.

168. Tang JY, Yan TT, Bao YJ, Shen CQ, Yu CY, Zhu XQ, Tian XL, Guo FF, Liang Q, Liu Q, et al. LncRNA GLCC1 promotes colorectal carcinogenesis and glucose metabolism by stabilizing c-Myc. Nat Commun. 2019;10. 
169. Cepeda D, Ng HF, Sharifi HR, Mahmoudi S, Cerrato VS, Fredlund E, Magnusson K, Nilsson H, Malyukova A, Rantala J, et al. CDK-mediated activation of the SCFFBXO28 ubiquitin ligase promotes MYC-driven transcription and tumourigenesis and predicts poor survival in breast cancer. Embo Mol Med. 2013;5:1067-86.

170. Popov N, Schulein C, Jaenicke LA, Eilers M. Ubiquitylation of the amino terminus of Myc by SCF beta-TrCP antagonizes SCFFbw7-mediated turnover. Nat Cell Biol. 2010;12:973-81.

171. Sun $X X$, He $X$, Yin L, Sears $R$, Dai MS. The nucleolar ubiquitin-specific protease USP36 deubiquitinates and stabilizes c-Myc. Cancer Res. 2015;75.

172. Pan J, Deng Q, Jiang C, Wang X, Niu T, Li H, Chen T, Jin J, Pan W, Cai X, et al. USP37 directly deubiquitinates and stabilizes c-Myc in lung cancer. Oncogene. 2015;34:3957-67.

173. Zhang WL, Liu ZK, Wang JM, Tian QB. Knockdown of USP28 enhances the radiosensitivity of esophageal cancer cells via the c-Myc/hypoxia-inducible factor-1 alpha pathway. J Cell Biochem. 2019;120:201-12.

174. Kim D, Hong A, Park HI, Shin WH, Yoo L, Jeon SJ, Chung KC. Deubiquitinating enzyme USP22 positively regulates C-Myc stability and tumorigenic activity in mammalian and breast cancer cells. J Cell Physiol. 2017;232:3664-76

175. Li X, Wu LM, Zopp M, Kopelov S, Du W. p53-TP53-induced glycolysis regulator mediated glycolytic suppression attenuates DNA damage and genomic instability in fanconi anemia hematopoietic stem cells. Stem Cells. 2019;37:937-47

176. Wade M, Wang YV, Wahl GM. The p53 orchestra: Mdm2 and Mdmx set the tone. Trends Cell Biol. 2010;20:299-309.

177. Barak Y, Juven T, Haffner R, Oren M. mdm2 expression is induced by wild type p53 activity. EMBO J. 1993;12:461-8.

178. Bang S, Kaur S, Kurokawa M. Regulation of the p53 family proteins by the ubiquitin proteasomal pathway. Int J Mol Sci. 2020:21.

179. Allton K, Jain AK, Herz HM, Tsai WW, Jung SY, Qin J, Bergmann A, Johnson RL, Barton MC. Trim24 targets endogenous p53 for degradation. Proc Natl Acad Sci U S A. 2009;106:11612-6.

180. Banks D, Wu M, Higa LA, Gavrilova N, Quan JM, Ye T, Kobayashi R, Sun H, Zhang H. L2DTL/CDT2 and PCNA interact with p53 and regulate p53 polyubiquitination and protein stability through MDM2 and CUL4A/DDB1 complexes. Cell Cycle. 2006;5:1719-29.

181. Luo K, Ehrlich E, Xiao ZX, Zhang WY, Ketner G, Yu XF. Adenovirus E4orF6 assembles with Cullin5-ElonginB-ElonginC E3 ubiquitin ligase through an HIV/SIV Vif-like BC-box to regulate p53. FASEB J. 2007;21:1742-50.

182. Luo Z, Ye X, Shou F, Cheng Y, Li F, Wang G. RNF115-mediated ubiquitination of p53 regulates lung adenocarcinoma proliferation. Biochem Biophys Res Commun. 2020.

183. Han YD, Tan Y, Zhao YY, Zhang YC, He XJ, Yu L, Jiang HP, Lu HJ, Tian HY. TRIM23 overexpression is a poor prognostic factor and contributes to carcinogenesis in colorectal cancer. J Cell Mol Med. 2020;24:5491-500.

184. Zhang YL, Cui NN, Zheng G. Ubiquitination of P53 by E3 ligase MKRN2 promotes melanoma cell proliferation. Oncol Lett. 2020;19:1975-84.

185. Weber JD, Taylor LJ, Roussel MF, Sherr CJ, Bar-Sagi D. Nucleolar Arf sequesters Mdm2 and activates p53. Nat Cell Biol. 1999;1:20-6.

186. Zhang WC, Gong J, Yang H, Wan LM, Peng YM, Wang XL, Sun J, Li F, Geng YQ, Li DY, et al. The mitochondrial protein MAVS stabilizes p53 to suppress tumorigenesis. Cell Rep. 2020;30:725.

187. Li XY, Guo MQ, Cai L, Du TT, Liu Y, Ding HF, Wang HB, Zhang JR, Chen XG, Yan $\mathrm{CH}$. Competitive ubiquitination activates the tumor suppressor p53. Cell Death Differ. 2020;27:1807-18.

188. Hu YN, Yu J, Wang Q, Zhang L, Chen XY, Cao Y, Zhao JP, Xu YJ, Jiang DS, Wang $Y$, Xiong WN. Tartrate-resistant acid phosphatase 5/ACP5 interacts with p53 to control the expression of SMAD3 in lung adenocarcinoma. Mol Ther Oncol. 2020;16:272-88.

189. Lim KH, Park JJ, Gu BH, Kim JO, Park SG, Baek KH. HAUSP-nucleolin interaction is regulated by p53-Mdm2 complex in response to DNA damage response. Sci Rep. 2015;5.

190. Yuan J, Luo KT, Zhang LZ, Cheville JC, Lou ZK. USP10 Regulates p53 Localization and Stability by Deubiquitinating p53. Cell. 2010;140:384-U121.

191. Liu WT, Huang KY, Lu MC, Huang HL, Chen CY, Cheng YL, Yu HC, Liu SQ, Lai NS, Huang HB. TGF-beta upregulates the translation of USP15 via the PI3K AKT pathway to promote p53 stability. Oncogene. 2017:36:2715-23.

192. Pu Q, LV YR, Dong K, Geng WW, Gao HD. Tumor suppressor OTUD3 induces growth inhibition and apoptosis by directly deubiquitinating and stabilizing p53 in invasive breast carcinoma cells. BMC Cancer. 2020;20:583.
193. Piao SD, Pei HZ, Huang B, Baek SH. Ovarian tumor domain-containing protein 1 deubiquitinates and stabilizes p53. Cell Signal. 2017;33:22-9.

194. Luo JD, Lu ZH, Lu XJ, Chen L, Cao JP, Zhang SY, Ling Y, Zhou XF. OTUD5 regulates p53 stability by deubiquitinating p53. PLoS One. 2013;8.

195. Zhang L, Gong F. Involvement of USP24 in the DNA damage response. Mol Cell Oncol. 2016:3:e1011888.

196. Liu J, Chung HJ, Vogt M, Jin Y, Malide D, He L, Dundr M, Levens D. JTV1 coactivates FBP to induce USP29 transcription and stabilize p53 in response to oxidative stress. EMBO J. 2011;30:846-58.

197. Hock AK, Vigneron AM, Carter S, Ludwig RL, Vousden KH. Regulation of p53 stability and function by the deubiquitinating enzyme USP42. EMBO J. 2011 30:4921-30.

198. Ke JY, Dai CJ, Wu WL, Gao JH, Xia AJ, Liu GP, Lv KS, Wu CL. USP11 regulates p53 stability by deubiquitinating p53. J Zhejiang Univ Sci B. 2014;15:1032-8.

199. Li M, Chen D, Shiloh A, Luo J, Nikolaev AY, Qin J, Gu W. Deubiquitination of p53 by HAUSP is an important pathway for p53 stabilization. Nature. 2002; 416:648-53.

200. Sheng Y, Saridakis V, Sarkari F, Duan S, Wu T, Arrowsmith CH, Frappier L. Molecular recognition of p53 and MDM2 by USP7/HAUSP. Nat Struct Mol Biol. 2006;13:285-91

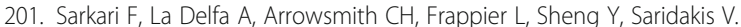
Further insight into substrate recognition by USP7: structural and biochemical analysis of the $\mathrm{HdmX}$ and $\mathrm{Hdm} 2$ interactions with USP7. J Mol Biol. 2010;402:825-37.

202. An T, Gong Y, Li X, Kong L, Ma P, Gong L, Zhu H, Yu C, Liu J, Zhou H, et al. USP7 inhibitor P5091 inhibits Wnt signaling and colorectal tumor growth. Biochem Pharmacol. 2017;131:29-39.

203. Xia X, Liao Y, Huang C, Liu Y, He J, Shao Z, Jiang L, Dou QP, Liu J, Huang $H$. Deubiquitination and stabilization of estrogen receptor alpha by ubiquitinspecific protease 7 promotes breast tumorigenesis. Cancer Lett. 2019;465: $118-28$

204. Fan YH, Cheng J, Vasudevan SA, Dou J, Zhang H, Patel RH, Ma IT, Rojas Y, Zhao Y, Yu Y, et al. USP7 inhibitor P22077 inhibits neuroblastoma growth via inducing p53-mediated apoptosis. Cell Death Dis. 2013:4:e867.

205. Masuya D, Huang C, Liu D, Nakashima T, Yokomise H, Ueno M, Nakashima $\mathrm{N}$, Sumitomo S. The HAUSP gene plays an important role in non-small cell lung carcinogenesis through p53-dependent pathways. J Pathol. 2006;208: 724-32.

206. Kruse JP, Gu W. MSL2 promotes Mdm2-independent cytoplasmic localization of p53. J Biol Chem. 2009;284:3250-63.

207. Yang YL, Ludwig RL, Jensen JP, Pierre SA, Medaglia MV, Davydov IV, Safiran YJ, Oberoi P, Kenten JH, Phillips AC, et al. Small molecule inhibitors of HDM2 ubiquitin ligase activity stabilize and activate p53 in cells. Cancer Cell. 2005:7:547-59.

208. Jiang J, Tam LM, Wang PC, Wang YS. Arsenite targets the RING finger domain of Rbx1 E3 ubiquitin ligase to inhibit proteasome-mediated degradation of Nrf2. Chem Res Toxicol. 2018;31:380-7.

209. Komatsu M, Kurokawa H, Waguri S, Taguchi K, Kobayashi A, Ichimura Y, Sou YS, Ueno I, Sakamoto A, Tong Kl, et al. The selective autophagy substrate p62 activates the stress responsive transcription factor Nrf2 through inactivation of Keap1. Nat Cell Biol. 2010;12:213-U217.

210. Wan ZH, Jiang TY, Shi YY, Pan YF, Lin YK, Ma YH, Yang C, Feng XF, Huang $L F$, Kong XN, et al. RPB5-mediating protein promotes cholangiocarcinoma tumorigenesis and drug resistance by competing with NRF2 for KEAP1 binding. Hepatology. 2020;71:2005-22.

211. Wang Q, Ma J, Lu Y, Zhang S, Huang J, Chen J, Bei JX, Yang K, Wu G, Huang $K$, et al. CDK20 interacts with KEAP1 to activate NRF2 and promotes radiochemoresistance in lung cancer cells. Oncogene. 2017;36:5321-30.

212. Liu YF, Tao SS, Liao LJ, Li Y, Li HC, Li ZH, Lin LL, Wan XC, Yang XL, Chen L. TRIM25 promotes the cell survival and growth of hepatocellular carcinoma through targeting Keap1-Nrf2 pathway. Nat Commun. 2020;11.

213. Xu PF, Jiang LP, Yang Y, Wu MG, Liu BY, Shi YL, Shen QS, Jiang XL, He YM, Cheng DT, et al. PAQR4 promotes chemoresistance in non-small cell lung cancer through inhibiting Nrf2 protein degradation. Theranostics. 2020;10: 3767-78.

214. Yu YP, Cai LC, Wang XY, Cheng SY, Zhang M, Jian WG, Wang TD, Yang JK, Yang KB, Zhang C. BMP8A promotes survival and drug resistance via Nrf2/ TRIM24 signaling pathway in clear cell renal cell carcinoma. Cancer Sci. 2020;111:1555-66

215. Lo JY, Spatola BN, Curran SP. WDR23 regulates NRF2 independently of KEAP1. Plos Genet. 2017;13. 
216. Cuadrado A. Structural and functional characterization of Nrf2 degradation by glycogen synthase kinase 3/beta-TrCP. Free Radic Biol Med. 2015;88:14757.

217. Wu TD, Zhao F, Gao BX, Tan C, Yagishita N, Nakajima T, Wong PK, Chapman E, Fang DY, Zhang DD. Hrd1 suppresses Nrf2-mediated cellular protection during liver cirrhosis. Genes Dev. 2014;28:708-22.

218. Zhang Q, Zhang ZY, Du H, Li SZ, Tu R, Jia YF, Zheng Z, Song XM, Du $\mathrm{RL}$, Zhang XD. DUB3 deubiquitinates and stabilizes NRF2 in chemotherapy resistance of colorectal cancer. Cell Death Differ. 2019;26: 2300-13.

219. Sun Y, He W, Luo M, Zhou Y, Chang G, Ren W, Wu K, Li X, Shen J, Zhao X, $\mathrm{Hu} Y$. SREBP1 regulates tumorigenesis and prognosis of pancreatic cancer through targeting lipid metabolism. Tumour Biol. 2015;36:4133-41.

220. Bakan I, Laplante M. Connecting mTORC1 signaling to SREBP-1 activation. Curr Opin Lipidol. 2012;23:226-34.

221. Zhao XP, Feng DR, Wang Q, Abdulla A, Xie XJ, Zhou J, Sun Y, Yang ES, Liu $L P$, Vaitheesvaran $B$, et al. Regulation of lipogenesis by cyclin-dependent kinase 8-mediated control of SREBP-1. J Clin Investig. 2012;122:2417-27.

222. Tu KS, Zheng X, Yin GZ, Zan XF, Yao YM, Liu QG. Evaluation of Fbxw7 expression and its correlation with expression of SREBP-1 in a mouse model of NAFLD. Mol Med Rep. 2012;6:525-30.

223. Walker AK, Yang FJ, Jiang KR, Ji JY, Watts JL, Purushotham A, Boss O, Hirsch ML, Ribich S, Smith JJ, et al. Conserved role of SIRT1 orthologs in fastingdependent inhibition of the lipid/cholesterol regulator SREBP. Genes Dev. 2010;24:1403-17.

224. Lee JP, Brauweiler A, Rudolph M, Hooper JE, Drabkin HA, Gemmill RM. The TRC8 ubiquitin ligase is sterol regulated and interacts with lipid and protein biosynthetic pathways. Mol Cancer Res. 2010;8:93-106.

225. Han SH, Korm S, Han YG, Choi SY, Kim SH, Chung HJ, Park K, Kim JY, Myung K, Lee JY, et al. GCA links TRAF6-ULK1-dependent autophagy activation in resistant chronic myeloid leukemia. Autophagy. 2019;15:2076-90.

226. Nazio F, Strappazzon F, Antonioli M, Bielli P, Cianfanelli V, Bordi M, Gretzmeier C, Dengjel J, Piacentini M, Fimia GM, Cecconi F. mTOR inhibits autophagy by controlling ULK1 ubiquitylation, self-association and function through AMBRA1 and TRAF6. Nat Cell Biol. 2013;15:406.

227. Chauhan S, Kumar S, Jain A, Ponpuak M, Mudd MH, Kimura T, Choi SW, Peters R, Mandell M, Bruun JA, et al. TRIMs and galectins globally cooperate and TRIM16 and galectin-3 co-direct autophagy in endomembrane damage homeostasis. Dev Cell. 2016;39:13-27.

228. Di Rienzo M, Antonioli M, Fusco C, Liu Y, Mari M, Orhon I, Refolo G, Germani F, Corazzari M, Romagnoli A, et al. Autophagy induction in atrophic muscle cells requires ULK1 activation by TRIM32 through unanchored K63-linked polyubiquitin chains. Sci Adv. 2019;5.

229. Raimondi M, Cesselli D, Di Loreto C, La Marra F, Schneider C, Demarchi F. USP1 (ubiquitin specific peptidase 1) targets ULK1 and regulates its cellular compartmentalization and autophagy. Autophagy. 2019;15:613-30.

230. Thayer JA, Awad O, Hegdekar N, Sarkar C, Tesfay H, Burt C, Zeng X, Feldman RA, Lipinski MM. The PARK10 gene USP24 is a negative regulator of autophagy and ULK1 protein stability. Autophagy. 2020;16:140-53.

231. Nazio F, Cecconi F. Autophagy up and down by outsmarting the incredible ULK. Autophagy. 2017;13:967-8.

232. Liu CC, Chen RH. KLHL20 links the ubiquitin-proteasome system to autophagy termination. Autophagy. 2016;12:890-1.

233. Kim JH, Seo D, Kim SJ, Choi DW, Park JS, Ha J, Choi J, Lee JH, Jung SM, Seo KW, et al. The deubiquitinating enzyme USP20 stabilizes ULK1 and promotes autophagy initiation. EMBO Rep. 2018;19.

234. Chang YY, Juhasz G, Goraksha-Hicks P, Arsham AM, Mallin DR, Muller LK, Neufeld TP. Nutrient-dependent regulation of autophagy through the target of rapamycin pathway. Biochem Soc Trans. 2009;37:232-6.

235. Shi CS, Kehrl JH. TRAF6 and A20 regulate lysine 63-linked ubiquitination of beclin-1 to control TLR4-induced autophagy. Sci Signal. 2010;3.

236. Xia PY, Wang S, Du Y, Zhao ZN, Shi L, Sun L, Huang GL, Ye BQ, Li C, Dai ZH, et al. WASH inhibits autophagy through suppression of Beclin 1 ubiquitination. EMBO J. 2013;32:2685-96.

237. Fusco C, Mandriani B, Di Rienzo M, Micale L, Malerba N, Cocciadiferro D, Sjottem E, Augello B, Squeo GM, Pellico MT, et al. TRIM50 regulates Beclin 1 proautophagic activity. Biochim Biophys Acta Mol Cell Res. 2018;1865:908-19.

238. Xu DC, Shan B, Sun HW, Xiao J, Zhu KZ, Xie XX, Li XY, Liang W, Lu XJ, Qian $\mathrm{LH}$, Yuan JY. USP14 regulates autophagy by suppressing K63 ubiquitination of Beclin 1. Genes Dev. 2016;30:1718-30.
239. Platta HW, Abrahamsen H, Thoresen SB, Stenmark H. Nedd4-dependent lysine-11-linked polyubiquitination of the tumour suppressor Beclin 1. Biochem J. 2012;441:399-406.

240. Xu CF, Feng K, Zhao XN, Huang SQ, Cheng YJ, Qian L, Wang YN, Sun HX, Jin M, Chuang TH, Zhang YY. Regulation of autophagy by E3 ubiquitin ligase RNF216 through BECN1 ubiquitination. Autophagy. 2014;10:2239-50.

241. Liu JL, Xia HG, Kim M, Xu LH, Li Y, Zhang LH, Cai Y, Norberg HV, Zhang T, Furuya $T$, et al. Beclin1 controls the levels of p53 by regulating the deubiquitination activity of USP10 and USP13. Cell. 2011;147:223-34.

242. Jin SH, Tian S, Chen YM, Zhang CX, Xie WH, Xia XJ, Cui J, Wang RF. USP19 modulates autophagy and antiviral immune responses by deubiquitinating beclin-1. EMBO J. 2016;35:866-80.

243. Ashkenazi A, Bento CF, Ricketts T, Vicinanza M, Siddiqi F, Pavel M, Squitieri $F$, Hardenberg MC, Imarisio S, Menzies FM, Rubinsztein DC. Polyglutamine tracts regulate beclin 1-dependent autophagy. Nature. 2017;545:108.

244. Xiao J, Zhang T, Xu DC, Wang HB, Cai Y, Jin TJ, Liu M, Jin MZ, Wu KJ, Yuan JY. FBXL20-mediated Vps34 ubiquitination as a p53 controlled checkpoint in regulating autophagy and receptor degradation. Genes Dev. 2015;29:18496.

245. Zhang T, Dong KY, Liang W, Xu DC, Xia HG, Geng JF, Najafov A, Liu M, Li $Y X$, Han XR, et al. G-protein-coupled receptors regulate autophagy by ZBTB16-mediated ubiquitination and proteasomal degradation of Atg14L. Elife. 2015;4.

246. Morel E, Dupont N, Codogno P. Autophagy regulation: RNF2 targets AMBRA1. Cell Res. 2014;24:1029-30.

247. Wan W, You ZY, Zhou L, Xu YF, Peng C, Zhou TH, Yi C, Shi Y, Liu W. mTORC1-regulated and HUWE1-mediated WIPI2 degradation controls autophagy flux. Mol Cell. 2018;72:303.

248. Kuang E, Okumura CYM, Sheffy-Levin S, Varsano T, Shu VCW, Qi JF, Niesman IR, Yang HJ, Lopez-Otin C, Yang WY, et al. Regulation of ATG4B stability by RNF5 limits basal levels of autophagy and influences susceptibility to bacterial infection (vol 8, e1003007, 2012). PLoS Genet. 2020;16.

249. Liu CH, Zhang Y, She XL, Fan L, Li PY, Feng JB, Fu HJ, Liu Q, Liu Q, Zhao CH, et al. A cytoplasmic long noncoding RNA LINC00470 as a new AKT activator to mediate glioblastoma cell autophagy. J Hematol Oncol. 2018;11.

250. Lee HJ, Li CF, Ruan D, He J, Montal ED, Lorenz S, Girnun GD, Chan CH. Nonproteolytic ubiquitination of hexokinase 2 by HectH9 controls tumor metabolism and cancer stem cell expansion. Nat Commun. 2019;10.

251. Jiao L, Zhang HL, Li DD, Yang KL, Tang J, Li X, Ji J, Yu Y, Wu RY, Ravichandran $S$, et al. Regulation of glycolytic metabolism by autophagy in liver cancer involves selective autophagic degradation of HK2 (hexokinase 2). Autophagy. 2018;14:671-84.

252. Huang MW, Xiong H, Luo DL, Xu BR, Liu HL. CSN5 upregulates glycolysis to promote hepatocellular carcinoma metastasis via stabilizing the HK2 protein. Exp Cell Res. 2020;388.

253. Okatsu K, lemura S, Koyano F, Go E, Kimura M, Natsume T, Tanaka K, Matsuda N. Mitochondrial hexokinase HKI is a novel substrate of the Parkin ubiquitin ligase. Biochem Biophys Res Commun. 2012;428:197-202.

254. Feng YL, Zhang Y, Cai Y, Liu RJ, Lu ML, Li TZM, Fu Y, Guo M, Huang HC, Ou YF, Chen YH. A20 targets PFKL and glycolysis to inhibit the progression of hepatocellular carcinoma. Cell Death Dis. 2020;11.

255. Lee JH, Liu R, Li J, Zhang CB, Wang YG, Cai QS, Qian X, Xia Y, Zheng YH, Piao YJ, et al. Stabilization of phosphofructokinase 1 platelet isoform by AKT promotes tumorigenesis. Nat Commun. 2017;8.

256. Shang $Y$, He J, Wang Y, Feng Q, Zhang Y, Guo J, Li J, Li S, Wang Y, Yan G, et al. CHIP/Stub1 regulates the Warburg effect by promoting degradation of PKM2 in ovarian carcinoma. Oncogene. 2017;36:4191-200.

257. Yuan P, Zhou YY, Wang R, Chen SY, Wang QQ, Xu ZJ, Liu Y, Yang HL. TRIM58 interacts with pyruvate kinase M2 to inhibit tumorigenicity in human osteosarcoma cells. Biomed Res Int. 2020;2020.

258. Liu K, Li FZ, Han HC, Chen Y, Mao ZB, Luo JY, Zhao YM, Zheng B, Gu W, Zhao WH. Parkin regulates the activity of pyruvate kinase M2. J Biol Chem. 2016;291:10307-17.

259. Choi HS, Pei CZ, Park JH, Kim SY, Song SY, Shin GJ, Baek KH. Protein stability of pyruvate kinase Isozyme M2 is mediated by HAUSP. Cancers (Basel). 2020;12.

260. Kim SR, Kim JO, Lim KH, Yun JH, Han I, Baek KH. Regulation of pyruvate kinase isozyme $M 2$ is mediated by the ubiquitin-specific protease 20. Int J Oncol. 2015:46:2116-24.

261. Wang Y, Ha SW, Zhang T, Kho DH, Raz A, Xie Y. Polyubiquitylation of AMF requires cooperation between the gp78 and TRIM25 ubiquitin ligases. Oncotarget. 2014;5:2044-51. 
262. Deng XQ, Yi X, Deng JY, Zou YQ, Wang SS, Shan WH, Liu P, Zhang ZB, Chen LF, Hao L. ROCK2 promotes osteosarcoma growth and metastasis by modifying PFKFB3 ubiquitination and degradation. Exp Cell Res. 2019;385.

263. Tudzarova S, Colombo SL, Stoeber K, Carcamo S, Williams GH, Moncada S. Two ubiquitin ligases, APC/C-Cdh1 and SKP1-CUL1-F (SCF)-beta-TrCP, sequentially regulate glycolysis during the cell cycle. Proc Natl Acad Sci U S A. 2011;108:5278-83.

264. Colombo SL, Palacios-Callender M, Frakich N, Carcamo S, Kovacs I, Tudzarova S, Moncada S. Molecular basis for the differential use of glucose and glutamine in cell proliferation as revealed by synchronized HeLa cells. Proc Natl Acad Sci U S A. 2011;108:21069-74.

265. Cai Q, Wang SH, Jin LY, Weng MZ, Zhou D, Wang JD, Tang ZH, Quan ZW. Long non-coding RNA GBCDRlnc1 induces chemoresistance of gallbladder cancer cells by activating autophagy. Mol Cancer. 2019;18.

266. Yu T, Zhao YJ, Hu ZX, Li J, Chu DD, Zhang JW, Li Z, Chen B, Zhang X, Pan $\mathrm{HY}$, et al. MetaLnc9 facilitates lung cancer metastasis via a PGK1-activated AKT/mTOR pathway. Cancer Res. 2017;77:5782-94.

267. Mikawa T, Maruyama T, Okamoto K, Nakagama H, Lleonart ME, Tsusaka T, Hori K, Murakami I, Izumi T, Takaori-Kondo A, et al. Senescence-inducing stress promotes proteolysis of phosphoglycerate mutase via ubiquitin ligase Mdm2. J Cell Biol. 2014;204:729-45.

268. Yoshino S, Hara T, Nakaoka HJ, Kanamori A, Murakami Y, Seiki M, Sakamoto T. The ERK signaling target RNF126 regulates anoikis resistance in cancer cells by changing the mitochondrial metabolic flux. Cell Discov. 2016;2.

269. Peng MX, Yang D, Hou YX, Liu SQ, Zhao MJ, Qin YL, Chen R, Teng Y, Liu MR. Intracellular citrate accumulation by oxidized ATM-mediated metabolism reprogramming via PFKP and CS enhances hypoxic breast cancer cell invasion and metastasis. Cell Death Dis. 2019;10.

270. Sun RC, Denko NC. Hypoxic regulation of glutamine metabolism through HIF1 and SIAH2 supports lipid synthesis that is necessary for tumor growth. Cell Metab. 2014;19:285-92.

271. Han C. Amplification of Usp13 drives ovarian cancer metabolism. Clin Cancer Res. 2019;25:90.

272. Wang M, Hu J, Yan LL, Yang YP, He M, Wu M, Li Q, Gong W, Yang Y, Wang $Y$, et al. High glucose-induced ubiquitination of G6PD leads to the injury of podocytes. FASEB J. 2019:33:6296-310.

273. Yu F, White SB, Zhao Q, Lee FS. HIF-1alpha binding to VHL is regulated by stimulus-sensitive proline hydroxylation. Proc Natl Acad Sci U S A. 2001;98: 9630-5.

274. Jin X, Pan Y, Wang L, Zhang L, Ravichandran R, Potts PR, Jiang J, Wu H, Huang H. MAGE-TRIM28 complex promotes the Warburg effect and hepatocellular carcinoma progression by targeting FBP1 for degradation. Oncogenesis. 2017;6:e312.

275. Jiang WQ, Wang SW, Xiao MT, Lin Y, Zhou LS, Lei QY, Xiong Y, Guan KL, Zhao SM. Acetylation regulates gluconeogenesis by promoting PEPCK1 degradation via recruiting the UBR5 ubiquitin ligase. Mol Cell. 2011;43:33-44.

276. Fernandes R, Carvalho A, Kumagai A, Seica R, Hosoya KI, Terasaki T, Murta J, Pereira P, Faro C. Downregulation of retinal GLUT1 in diabetes by ubiquitinylation. Mol Vis. 2004;10:618-28.

277. Cheng A, Zhang M, Gentry MS, Worby CA, Dixon JE, Saltiel AR. A role for AGL ubiquitination in the glycogen storage disorders of Lafora and Cori's disease. Genes Dev. 2007;21:2399-409.

278. Zhang C, Liu J, Zhao YH, Yue XT, Wu H, Li J, Shen ZY, Haffty B, Hu WW, Feng ZH. Cullin3-KLHL25 ubiquitin ligase targets ACLY for degradation to inhibit lipid synthesis and tumor progression. Cancer Res. 2017;77.

279. Gu L, Zhu Y, Lin X, Lu B, Zhou X, Zhou F, Zhao Q, Prochownik EV, Li Y. The IKKbeta-USP30-ACLY axis controls Lipogenesis and tumorigenesis. Hepatology. 2020.

280. Qi L, Heredia JE, Altarejos JY, Screaton R, Goebel N, Niessen S, MacLeod IX, Liew CW, Kulkarni RN, Bain J, et al. TRB3 links the E3 ubiquitin ligase COP1 to lipid metabolism. Science. 2006;312:1763-6.

281. Ma J, Yan RL, Zu X, Cheng JM, Rao K, Liao DF, Cao DL. Aldo-keto reductase family 1 B10 affects fatty acid synthesis by regulating the stability of acetylCoA carboxylase-alpha in breast cancer cells. J Biol Chem. 2008;283:3418-23.

282. Yu JX, Deng R, Zhu HH, Zhang SS, Zhu CH, Montminy M, Davis R, Feng GS. Modulation of fatty acid synthase degradation by concerted action of p38 MAP kinase, E3 ligase COP1, and SH2-tyrosine phosphatase Shp2. J Biol Chem. 2013;288:3823-30.

283. Gang XK, Xuan LL, Zhao X, Lv Y, Li F, Wang Y, Wang GX. Speckle-type POZ protein suppresses lipid accumulation and prostate cancer growth by stabilizing fatty acid synthase. Prostate. 2019;79:864-71.
284. Calvisi DF, Wang CM, Ho C, Ladu S, Lee SA, Mattu S, Destefanis G, Delogu S, Zimmermann A, Ericsson J, et al. Increased lipogenesis, induced by AKTmTORC1-RPS6 signaling, promotes development of human hepatocellular carcinoma. Gastroenterology. 2011;140:1071-U1542.

285. Graner E, Tang D, Rossi S, Baron A, Migita T, Weinstein L, Lechpammer M, Huesken D, Zimmermann J, Signoretti S, Loda M. The isopeptidase USP2a regulates the stability of fatty acid synthase in prostate cancer. Cancer Cell. 2004;5:253-61.

286. Menzies SA, Volkmar N, van den Boomen DJ, Timms RT, Dickson AS, Nathan JA, Lehner PJ. The sterol-responsive RNF145 E3 ubiquitin ligase mediates the degradation of HMG-CoA reductase together with gp78 and Hrd1. Elife. 2018;7.

287. Jiang LY, Jiang W, Tian N, Xiong YN, Liu J, Wei J, Wu KY, Luo J, Shi XJ, Song BL. Ring finger protein 145 (RNF145) is a ubiquitin ligase for sterol-induced degradation of HMG-CoA reductase. J Biol Chem. 2018;293:4047-55.

288. Loregger A, Raaben M, Tan J, Scheij S, Moeton M, van den Berg M, GelbergEtel H, Stickel E, Roitelman J, Brummelkamp T, Zelcer N. Haploid mammalian genetic screen identifies UBXD8 as a key determinant of HMGC $R$ degradation and cholesterol biosynthesis. Arterioscler Thromb Vasc Biol. 2017;37:2064

289. Hwang S, Nguyen AD, Jo Y, Engelking LJ, Brugarolas J, DeBose-Boyd RA. Hypoxia-inducible factor 1alpha activates insulin-induced gene 2 (Insig-2) transcription for degradation of 3-hydroxy-3-methylglutaryl (HMG)-CoA reductase in the liver. J Biol Chem. 2017;292:9382-93.

290. Gelsomino G, Corsetto PA, Campia I, Montorfano G, Kopecka J, Castella B, Gazzano E, Ghigo D, Rizzo AM, Riganti C. Omega 3 fatty acids chemosensitize multidrug resistant colon cancer cells by down-regulating cholesterol synthesis and altering detergent resistant membranes composition. Mol Cancer. 2013;12.

291. Foresti O, Ruggiano A, Hannibal-Bach HK, Ejsing CS, Carvalho P. Sterol homeostasis requires regulated degradation of squalene monooxygenase by the ubiquitin ligase Doa10/Teb4. Elife. 2013;2:e00953.

292. Zelcer N, Hong C, Boyadjian R, Tontonoz P. LXR regulates cholesterol uptake through idol-dependent ubiquitination of the LDL receptor. Science. 2009; 325:100-4.

293. Lee DE, Yoo JE, Kim J, Kim S, Kim S, Lee H, Cheong HS. NEDD4L downregulates autophagy and cell growth by modulating ULK1 and a glutamine transporter. Cell Death Dis. 2020;11.

294. Jeon YJ, Khelifa S, Ratnikov B, Scott DA, Feng YM, Parisi F, Ruller C, Lau E, Kim H, Brill LM, et al. Regulation of glutamine carrier proteins by RNF5 determines breast cancer response to ER stress-inducing chemotherapies. Cancer Cell. 2015;27:354-69.

295. Zhao S, Wang JM, Yan J, Zhang DL, Liu BQ, Jiang JY, Li C, Li S, Meng XN, Wang HQ. BAG3 promotes autophagy and glutaminolysis via stabilizing glutaminase. Cell Death Dis. 2019;10.

296. Zhao JZ, Zhou R, Hui KY, Yang Y, Zhang QY, Ci YL, Shi L, Xu CM, Huang F, Hu Y. Selenite inhibits glutamine metabolism and induces apoptosis by regulating GLS1 protein degradation via APC/C-CDH1 pathway in colorectal cancer cells. Oncotarget. 2017;8:18832-47.

297. Liu J, Zhang C, Wu H, Sun XX, Li Y, Huang S, Yue X, Lu SE, Shen Z, Su X, et al. Parkin ubiquitinates phosphoglycerate dehydrogenase to suppress serine synthesis and tumor progression. J Clin Invest. 2020;130:3253-69.

298. Anderson DD, Eom JY, Stover PJ. Competition between sumoylation and ubiquitination of serine hydroxymethyltransferase 1 determines its nuclear localization and its accumulation in the nucleus. J Biol Chem. 2012;287: 4790-9.

299. Li Z, Zhang H. Reprogramming of glucose, fatty acid and amino acid metabolism for cancer progression. Cell Mol Life Sci. 2016;73:377-92.

300. Cui D, Xiong $X$, Shu J, Dai $X$, Sun $Y$, Zhao Y. FBXW7 confers radiation survival by targeting p53 for degradation. Cell Rep. 2020;30:497-509 e494.

\section{Publisher's Note}

Springer Nature remains neutral with regard to jurisdictional claims in published maps and institutional affiliations. 